A Career in Catalysis: Alexis T. Bell

Fuat Celik, Rutgers University

Baron Peters, University of California, Santa Barbara

Marc-Olivier Coppens, University College London (ORCID = 0000-0002-1810-2537)

Alon McCormick, ${ }^{*}$ University of Minnesota (ORCID = 0000-0002-8885-1330)

Bob Hicks, University of California, Los Angeles

John Ekerdt, University of Texas (ORCID = 0000-0002-1788-5330)

\begin{abstract}
$\underline{\text { Abstract }}$
On the occasion of Alexis T. Bell's fiftieth year at Berkeley, we are honored to discuss a few aspects of his extensive contributions to catalysis, reaction engineering, and understanding of molecular scale structure in catalytic processes. The illustrations provided here help reveal some of his traits most valued by our community: a drive to employ the best methods of instrumentational and computational analysis available; the instinct to search for the essence of the most important problems at hand, and the skill to write about them with exceptional clarity; and the formation and nurturing of collaborative teams to focus on the most essential questions.

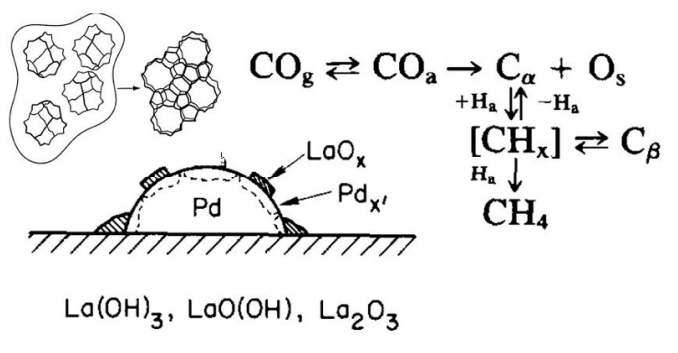

*Corresponding Author: email: mccormic@umn.edu
\end{abstract}

\title{
Introduction
}

The authors assembled for this account of course do not presume to strive for an overview of Alex Bell's contributions of 50 years. With around 700 papers and around 180 students and postdoctoral associates (not even trying to count how many active collaborators!), 
his career to date spans such broad and important problems that it would require a substantial Festschrift to even attempt to do any justice to the work (Supporting Information). Nevertheless, as a collection of former group members spanning several decades $(2010,2004,1998,1987$, 1984, and 1979), rather than being comprehensive we aim to share a representative set of vignettes - a window into Alex' approaches and patterns that, we think, illustrate his enduring impact on the field. These are arranged roughly chronologically, addressing chemical vapor deposition, characterization of catalysts and catalytic processes, $\mathrm{CO}$ hydrogenation on supported metals, zeolite synthesis and design, partial oxidation on metal oxides, and quantum mechanical and statistical mechanical computation.

With these vignettes, too, we hope to show glimpses of Alex's keen insight and mentoring expertise that stand out for us, certainly influencing our own careers and interests, but more broadly also establishing currents in the whole catalysis community. Finally, we briefly reflect on his personal influence on generations of students and collaborators. We offer apologies in advance to our many peers who could easily offer even more compelling and interesting stories about Alex's influence and contributions, but we are confident that they would all join us in celebrating his achievements and continuing to pass on the lessons learned from him.

\section{The Early Years}

Alexis T. Bell's earliest professional contributions were in the reaction engineering of plasma processes. His research over the first decade explored the mechanisms and kinetics of the plasma-enhanced chemical vapor deposition of inorganic and organic films. Through a series of papers published throughout the 70's and early 80's, Alex applied reaction engineering modeling to advance mechanistic descriptions of plasma chemistry and thin film growth (Figures 
1 and 2)..$^{e . g .1-10}$ In this work, we see the emergence of Alex's approach towards scientific research: identify the important questions; master the spectroscopic and numerical tools needed to address the problem; determine the detailed reaction chemistry; and then share with the community the relationship between the reaction chemistry and process performance.

\section{Table I}

Reaction Mechanism for Plasma Polymerization of Unsaturated Hydrocarbons ${ }^{a}$

Initiation

1. $\mathrm{e}+\mathrm{M}_{\mathrm{g}} \rightarrow \mathrm{M}_{\mathrm{g}}^{\prime}+\mathrm{H}_{2}+\mathrm{e}$

2. $\mathrm{e}+\mathrm{M}_{\mathrm{g}} \rightarrow \mathrm{M}_{\mathrm{g}}^{\prime}+2 \mathrm{H}+\mathrm{e}$

3. $\mathrm{e}+\mathrm{M}_{\mathrm{g}} \rightarrow 2 \mathrm{R} \cdot \mathrm{g}+\mathrm{e}$

4. e $+\mathrm{H}_{2} \rightarrow 2 \mathrm{H} \cdot+\mathrm{e}$

Propagation (homogeneous)

5. $\mathrm{H} \cdot+\left[\begin{array}{c}\mathrm{M}_{\mathrm{g}} \\ \mathrm{M}_{\mathrm{g}}^{\prime}\end{array}\right\} \rightarrow \mathrm{R} \cdot \mathrm{g}_{\mathrm{g}_{1}}$

6. $R \cdot \cdot_{g_{n}}+\left\{\begin{array}{l}M_{g} \\ M_{g}^{\prime}\end{array}\right\} \rightarrow R_{g_{n+1}}$
Adsorption

7. $\mathrm{S}+\left\{\begin{array}{l}\mathrm{M}_{\mathrm{g}} \\ \mathrm{M}_{\mathrm{g}}^{\prime}\end{array}\right\} \rightarrow\left\{\begin{array}{l}\mathrm{M}_{\mathrm{s}} \\ \mathrm{M}_{\mathrm{s}}^{\prime}\end{array}\right\}$

8. $\mathrm{S}+\mathrm{H} \cdot \rightarrow \mathrm{H} \cdot \mathrm{s}$

9. $\mathrm{S}+\mathrm{R} \cdot \mathrm{g}_{n} \rightarrow \mathrm{R} \cdot \mathrm{s}_{n}$

Propagation (heterogeneous)

10. $\mathrm{R}_{\boldsymbol{s}_{n}}+\left\{\begin{array}{l}\mathrm{M}_{\mathrm{g}} \\ \mathrm{M}_{\mathrm{g}}^{\prime}\end{array}\right\} \rightarrow \mathrm{R}_{\boldsymbol{s}_{n+1}}$

11. $R \cdot_{s_{n}}+\left\{\begin{array}{l}M_{s} \\ M_{s}^{\prime}\end{array}\right\} \rightarrow R \cdot s_{s_{n+1}}$

12. $\mathrm{H} \cdot{ }_{\mathrm{s}}+\mathrm{H} \cdot \rightarrow \mathrm{H}_{2}$
Termination

13. $\mathrm{R} \cdot \mathrm{g}_{m}+\mathrm{H} \cdot \rightarrow \mathrm{P}_{\mathrm{g}_{m}}$

14. $\mathrm{R} \cdot \mathrm{g}_{m}+\mathrm{R} \cdot \mathrm{g}_{n} \rightarrow \mathrm{P}_{\mathrm{g}_{m+n}}$

15. $\mathrm{R} \cdot \mathrm{g}_{m}+\mathrm{R} \cdot \mathrm{s}_{n} \rightarrow \mathrm{P}_{\mathrm{s}_{m+n}}$

16. $R \cdot s_{s_{m}}+R \cdot s_{s_{n}} \rightarrow P_{s_{m+n}}$

17. $\mathrm{e}+\mathrm{P}_{\mathrm{g}_{m+n}} \rightarrow \mathrm{R}_{\mathrm{g}_{m}}+\mathrm{R}_{\mathrm{g}_{n}}$

18. $\mathrm{P}_{\mathrm{s}} \stackrel{\mathrm{e}, h \nu, \mathrm{I}^{+}}{\longrightarrow} \mathrm{R} \cdot{\mathrm{s}_{m}}+\mathrm{R} \cdot \mathrm{s}_{n}$

19. $\mathrm{H} \cdot+\mathrm{P}_{\mathrm{g}_{n}} \rightarrow \mathrm{R} \cdot \mathrm{g}_{n}+\mathrm{H}_{2}$

20. $\mathrm{H} \cdot+\mathrm{P}_{\mathrm{s}_{n}} \rightarrow \mathrm{R} \cdot \mathrm{s}_{n}+\mathrm{H}_{2}$

${ }^{a} \mathrm{M}_{\mathrm{g}}$, primary monomer; $\mathrm{R}_{\mathrm{g}}$, gas phase free radical; $\mathrm{P}_{\mathrm{g}}$, gas phase oligomer; $\mathrm{M}_{\mathrm{g}}^{\prime}$, derivative monomer; $\mathrm{R}_{\mathrm{g}}$, surface free radical; $\mathrm{P}_{\mathrm{s}}$, polymer fragment; $\mathrm{H}$, hydrogen atom.

Figure 1. Sequence of elementary reactions expected to occur when a hydrocarbon monomer enters a discharge zone of a DC plasma reactor. ${ }^{8}$ 


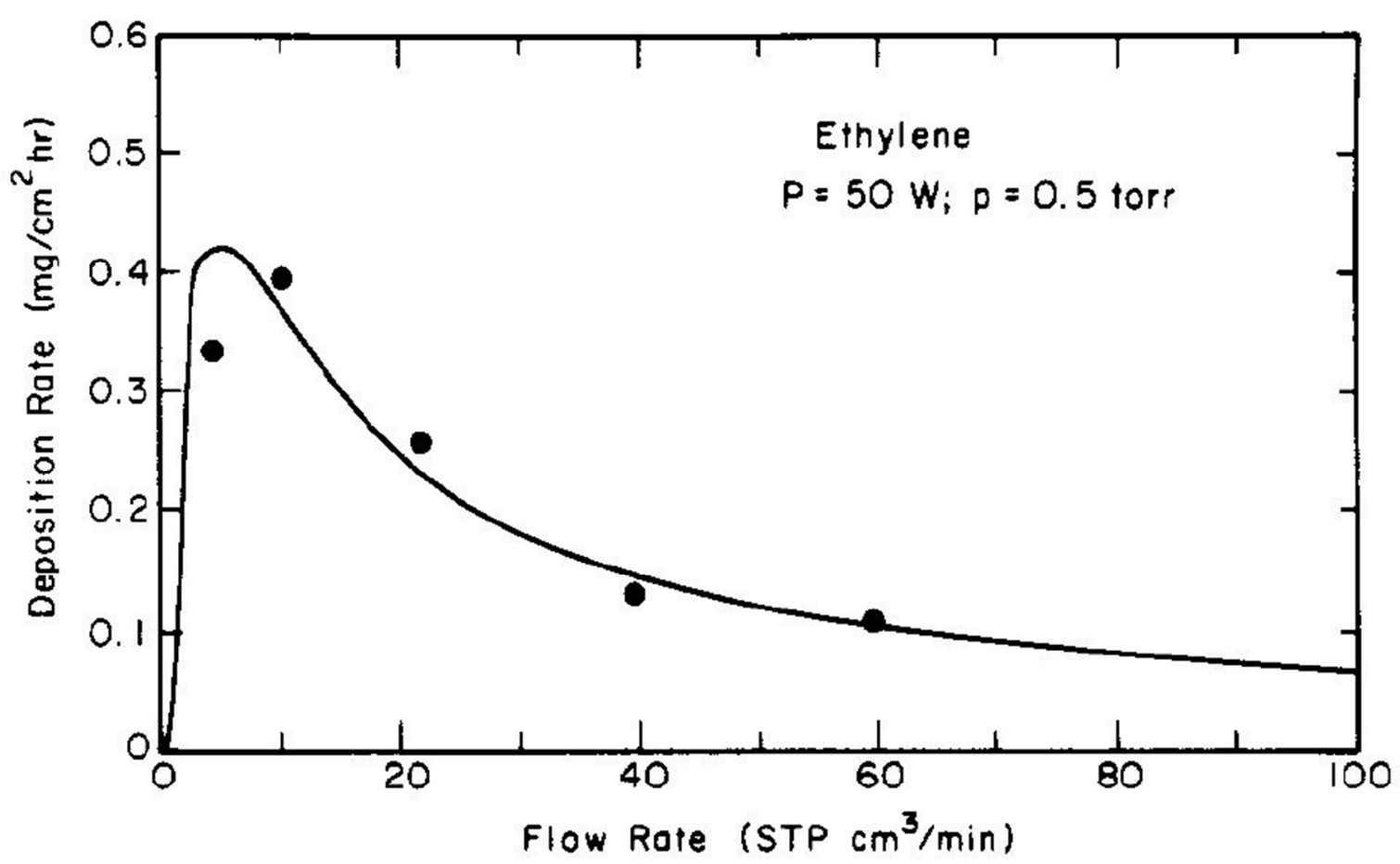

Figure 2. The rate of polymerization, which is the sum of gas and surface propagation steps was determined by solving the material balance equations that describe the monomer and free radical concentrations as a function of axial and radial position in the flow reactor. Predicted and experimental rates of polymer deposition as a function of monomer flow rate are one illustration of this model fit. ${ }^{8}$

Air pollution and energy security were major societal challenges of the early 70's. This created opportunities for exciting new research. Catalysis offered great promise in solving two major societal needs: (1) removing harmful pollutants from automotive exhaust; and (2) producing synthetic fuels to meet the energy crisis created by the U.S. oil embargo. Thus began the research program that is the foundation of Alex's career in catalysis. He started by addressing nitric oxide reduction ${ }^{11,12}$ and then moved on to Fischer-Tropsch synthesis and carbon monoxide hydrogenation to methanol. ${ }^{13-18}$

Alex's key motivation was to understand how catalyst structure affects selectivity, activity, and yield. Taking to heart the message over Latimer lecture hall, i.e., that "progress in 
science is based on advances in instrumentation", he built a state-of-the-art laboratory for probing the active sites on catalysts. In situ infrared (IR) spectroscopy was employed during adsorption and reaction of NO and CO on supported precious metal catalysts (Figure 3). ${ }^{\text {e.g., }}$ 14,19-

${ }^{25}$ He developed the first micro-reactor for observing the infrared spectra of adsorbed NO and CO under the high-pressure conditions employed in Fischer-Tropsch synthesis. ${ }^{26-28}$ Dramatic $^{2}$ changes in crystallite surface structure were discovered, depending on the composition of the metal oxide support and the method of preparing the catalyst. In situ Raman spectroscopy and

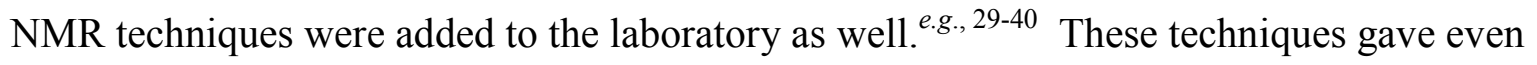
greater insight into the evolution of the catalyst under reaction conditions. The Bell group discovered how metal crystallites transformed in the reaction environment, how they interacted with the support and additives, and how the nature of the active sites changed with time during catalysis. $^{\text {e.g., }}$ 41-57

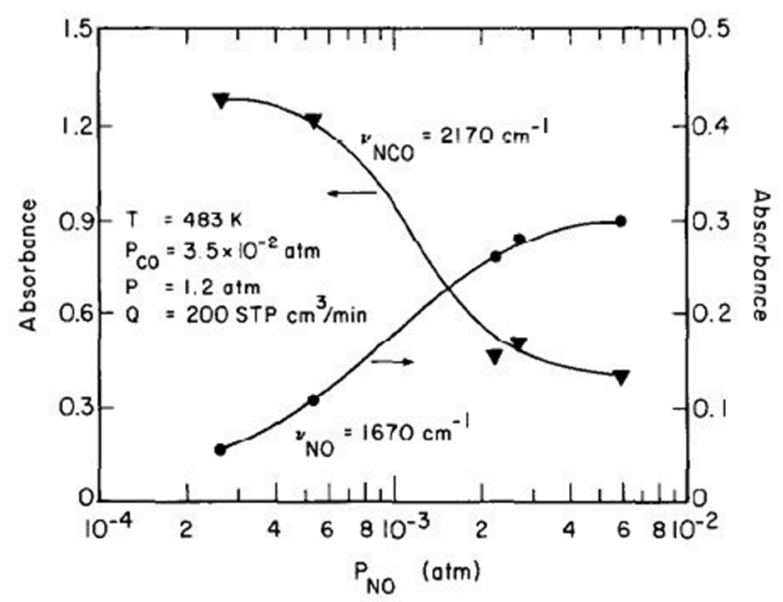

1. $\mathrm{NO}+\mathrm{S} \leftrightarrow \mathrm{NO}_{\mathrm{a}}$

2. $\mathrm{CO}+\mathrm{S} \rightarrow \mathrm{CO}_{\mathrm{a}}$

3. $\mathrm{NO}_{\mathrm{a}}+\mathrm{S} \rightarrow \mathrm{N}_{\mathrm{a}}+\mathrm{O}_{\mathrm{a}}$

4. $\mathrm{NO}_{\mathrm{a}}+\mathrm{N}_{\mathrm{a}} \rightarrow \mathrm{N}_{2} \mathrm{O}+2 \mathrm{~S}$

5. $\mathrm{NO}_{\mathrm{a}}+\mathrm{N}_{\mathrm{a}} \rightarrow \mathrm{N}_{2}+\mathrm{O}_{\mathrm{a}}+\mathrm{S}$

6. $\mathrm{CO}_{\mathrm{a}}+\mathrm{O}_{\mathrm{a}} \rightarrow \mathrm{CO}_{2}+2 \mathrm{~S}$

7. $\mathrm{N}_{\mathrm{a}}+\mathrm{CO} \leftrightarrow \mathrm{NCO}_{\mathrm{a}}$

Figure 3. Dependence of the $\mathrm{Rh}-\mathrm{NCO}$ and $\mathrm{Rh}-\mathrm{NO}^{\delta-}$ absorbance bands as a function of NO partial pressure. During the reduction of $\mathrm{NO}$ by $\mathrm{CO}$ over a $\mathrm{Rh} / \mathrm{SiO}_{2}$ catalyst an isocyanate group is formed on the surface of the rhodium microcrystallites. The dependence of the Rh-NCO band intensity on partial pressures of $\mathrm{NO}$ and $\mathrm{CO}$ can be interpreted with the aid of the reaction mechanism. ${ }^{24}$ 
Alex pioneered transient techniques to complement his work on steady-state reaction rate chemistry. He and his students investigated the response of the adsorbates and the reaction products to temperature transients and to isotopic substitution. This allowed Alex to refine the

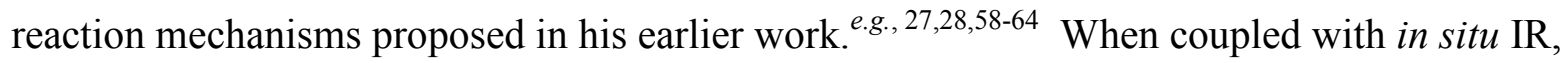
Raman and NMR spectroscopy, he was able to elucidate the key rate-determining steps occurring on the surface of the metal catalysts, and to distinguish between the active and the spectator adsorbates (Figure 4). ${ }^{29,31,61,65}$ This combination of experimental techniques - developed and advanced by Alex, his students and collaborators - contributed to our current molecular-level understanding of relationship between catalyst structure and its function.
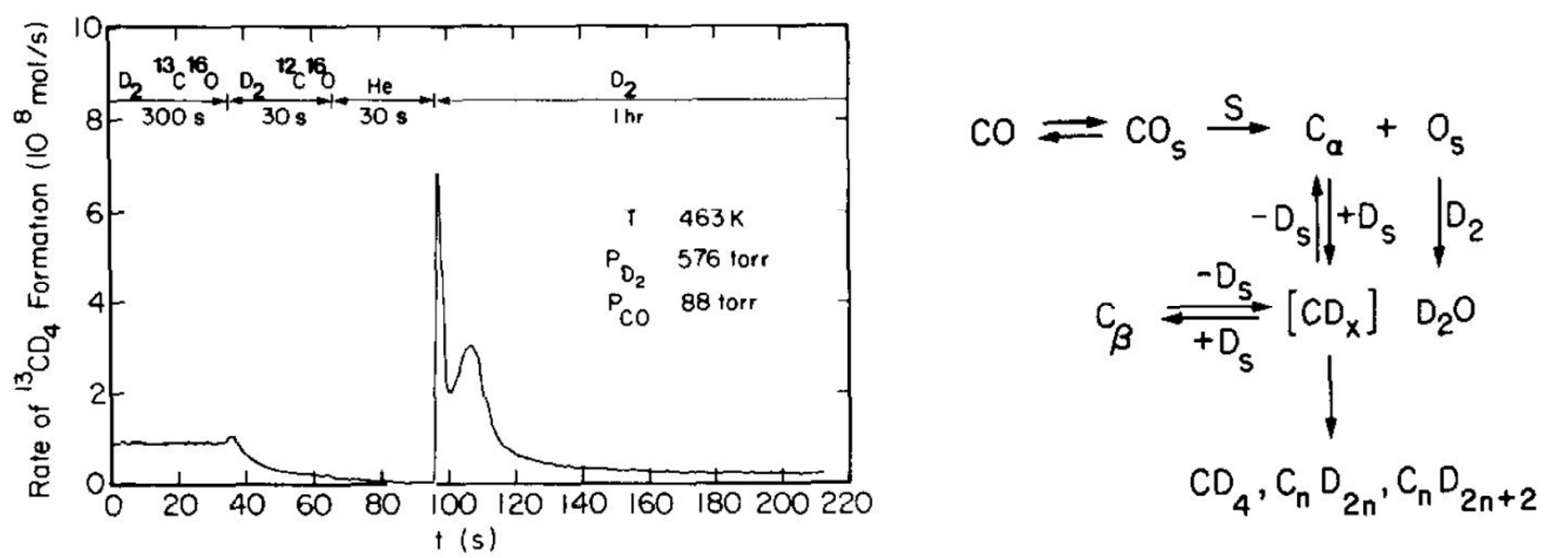

Figure 4. Transient response and isotope tracer studies revealed two distinctly different forms of carbon formed on $\mathrm{Ru} / \mathrm{SiO}_{2}$ during $\mathrm{CO}$ hydrogenation. $\mathrm{C}_{\alpha}$ is highly reactive and is the principle precursor to $\mathrm{C}_{2+}$ hydrocarbons and methane. $\mathrm{C}_{\beta}$ accumulates slower than $\mathrm{C}_{\alpha}$ and resides on $\mathrm{Ru}$ and the support. ${ }^{27}$

A hallmark of Alex's research program was to bring together the best researchers, and share their ideas on how to tackle the many unanswered questions in catalysis. The Bell and Somorjai groups met weekly at Lawrence Berkeley National Laboratory to discuss their latest achievements. Structure sensitivity, intrinsic kinetics, and catalyst design were often the focus of these meetings. Several times a year, Alex Bell and Michel Boudart's students would meet to 
compare the latest results from their respective labs. Students discussed the importance of identifying the active sites, looking for rate-limiting steps, and presenting rates in terms of turnover numbers. Detente between the USSR and the USA created a special opportunity to collaborate with scientists from the Institute of Catalysis in Novosibirsk. Doctors Davydov, Kuznetsov and Ryndin came to Berkeley and brought exciting new approaches to catalyst synthesis. ${ }^{66-69}$ [Yuri Ryndin even taught members of the group how to drink liquid nitrogen straight out of the Dewar!] Alex's students benefited here again from his mentorship. He taught us that scientific inquiry is a team effort; that to make breakthroughs one must embrace different viewpoints and learn new methods. Collaboration is key to staying at the forefront of engineering innovation and research.

\section{Carbon Monoxide Hydrogenation on Supported Metal Catalysts}

One guiding principle in Alex's overall approach to understanding Fischer-Tropsch and methanol synthesis is that catalyst science is advanced through understanding the structure of adsorbed species and the dynamics of elementary processes involved in catalyzed reactions. Starting with a description of the reaction pathways he and his students worked to develop a detailed mechanism based on establishing the adsorbed species under reaction conditions and the chemical nature of the key reaction intermediate(s) in the process. This mechanism was then tested and refined against steady-state and transient measurements to establish the dynamics of the elementary processes. The mechanistic and dynamics insight also allowed the group to address the nature of the active site and how the catalyst could be designed to improve activity, selectivity, and in turn, yield of the desired products.

Infrared observations, ${ }^{14,22}$ reactive scavenging ${ }^{15,70}$ and kinetic isotope effects ${ }^{16,59}$ led to a mechanism that has $\mathrm{CO}$ dissociating and carbon being hydrogenated to methylene and methyl 
groups, two key reaction intermediates (Fig 5). Hydrogenation of methyl produces methane and insertion of methylene into methyl produces an alkyl group that can continue to increase in carbon number by the insertion of additional methylene groups. During the early studies, it was noted that carbon was accumulating on the surface of the catalyst and not all the carbon was directly converted into products as indicated in Fig 5. This led to the proposal ${ }^{17,27,32,59,65,71}$ that carbon resided in a carbidic form, $\mathrm{C}_{\alpha}$, and an alkyl form, $\mathrm{C}_{\beta}$ (Fig 6).
1. $\mathrm{CO}+\mathrm{S} \rightleftarrows \mathrm{CO}_{\mathrm{s}}$
2. $\quad \mathrm{CO}_{\mathrm{s}}+\mathrm{S} \rightleftarrows \mathrm{C}_{\mathrm{s}}+\mathrm{O}_{\mathrm{s}}$
3. $\mathrm{H}_{2}+2 \mathrm{~S} \rightleftarrows 2 \mathrm{H}_{\mathrm{s}}$
4. $\quad \mathrm{H}_{2}+\mathrm{O}_{\mathrm{s}} \rightleftarrows \mathrm{H}_{2} \mathrm{O}+\mathrm{S}$
5. $\quad \mathrm{C}_{\mathrm{s}}+\mathrm{H}_{\mathrm{s}} \rightleftarrows \mathrm{CH}_{\mathrm{s}}+\mathrm{S}$
6. $\quad \mathrm{CH}_{\mathrm{s}}+\mathrm{H}_{\mathrm{s}} \rightleftarrows \mathrm{CH}_{2 \mathrm{~s}}+\mathrm{S}$
7. $\mathrm{CH}_{2 \mathrm{~s}}+\mathrm{H}_{\mathrm{s}} \rightleftarrows \mathrm{CH}_{3 \mathrm{~s}}+\mathrm{S}$
8. $\quad \mathrm{CH}_{3 \mathrm{~s}}+\mathrm{H}_{\mathrm{s}} \rightarrow \mathrm{CH}_{4}+2 \mathrm{~S}$
9. $\mathrm{CH}_{3 \mathrm{~s}}+\mathrm{CH}_{2 \mathrm{~s}} \rightarrow \mathrm{C}_{2} \mathrm{H}_{5 \mathrm{~s}}+\mathrm{S}$
10. $\quad \mathrm{C}_{2} \mathrm{H}_{5 \mathrm{~s}}+\mathrm{S} \rightarrow \mathrm{C}_{2} \mathrm{H}_{4}+\mathrm{H}_{\mathrm{s}}+\mathrm{S}$
11. $\mathrm{C}_{2} \mathrm{H}_{5 \mathrm{~s}}+\mathrm{H}_{\mathrm{s}} \rightarrow \mathrm{C}_{2} \mathrm{H}_{6}+2 \mathrm{~S}$
12. $\mathrm{C}_{2} \mathrm{H}_{5 \mathrm{~s}}+\mathrm{CH}_{2 \mathrm{~s}} \rightarrow \mathrm{C}_{3} \mathrm{H}_{7 \mathrm{~s}}+\mathrm{S}$ etc.

Figure 5. Proposed mechanism of hydrocarbon synthesis from $\mathrm{CO}$ and $\mathrm{H}_{2}{ }^{18}$

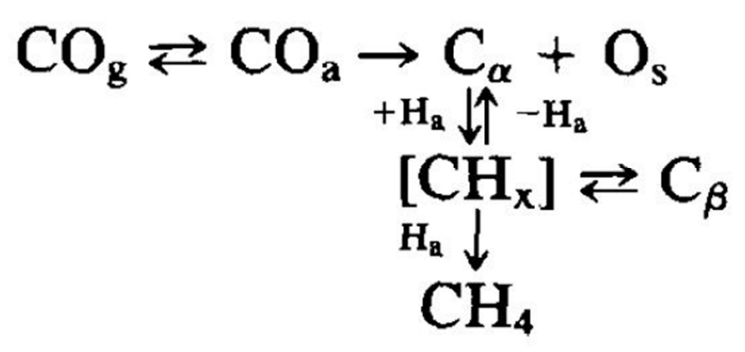

Figure 6. Reaction scheme for the rapid equilibration of $\mathrm{CO}$ into adsorbed $\mathrm{CO}$ and the interconversion of dissociated $\mathrm{CO}$ into the various forms of carbon. ${ }^{61}$

Alex adapted transient techniques (temperature programmed surface reaction (TPSR) and isotope switching) and established collaborations to bring in situ NMR spectroscopy to bear on 
identifying where the carbon resided, and how the different forms of carbon interconverted on an active catalyst. $^{31,32}$ The NMR signatures for carbidic and alkyl carbon were established as well as the carbon that migrated from the metal to the support. Rates of interconversion of the carbidic and alkyl carbon were established with transient techniques. ${ }^{61}$ This understanding was used in later studies to improve selectivity and yield.

Bell and coworkers discovered that methanol synthesis over palladium is strongly dependent on the composition of the support. ${ }^{43,44,69}$ Shown in Figure 7 is the effect of temperature and support type on the turnover frequency for carbon monoxide conversion into methanol. ${ }^{69}$ The intrinsic rate varies by over two orders of magnitude with the lowest rate observed for palladium black and the highest for palladium dispersed over lanthanum oxide. Characterization of the $\mathrm{Pd}$ on $\mathrm{La}_{2} \mathrm{O}_{3}$ by X-ray photoemission spectroscopy and infrared spectroscopy of adsorbed $\mathrm{CO}$ revealed that a thin covering of rare earth oxide migrates onto the metal crystallites. A schematic of this unique catalyst structure is shown in Figure $8 .{ }^{44}$ The migration of partially reduced $\mathrm{LaO}_{x}$ species onto the palladium is evidenced by a negative shift in the $\mathrm{Pd} 3 d_{5 / 2}$ binding energy by as much as $0.7 \mathrm{eV}$ below that for Pd dispersed on a noninteracting support $\left(\right.$ e.g., $\left.\mathrm{SiO}_{2}\right) .{ }^{43}$ In addition, the $\mathrm{LaO}_{\mathrm{x}}$ species suppress carbon monoxide adsorption on the metal crystallites, and weaken the Pd-CO sigma bond strength. ${ }^{44}$ Surprisingly, the extent of the metal-support interaction, i.e., the fractional coverage of rare earth oxide on the palladium increases with the metal particle size. 


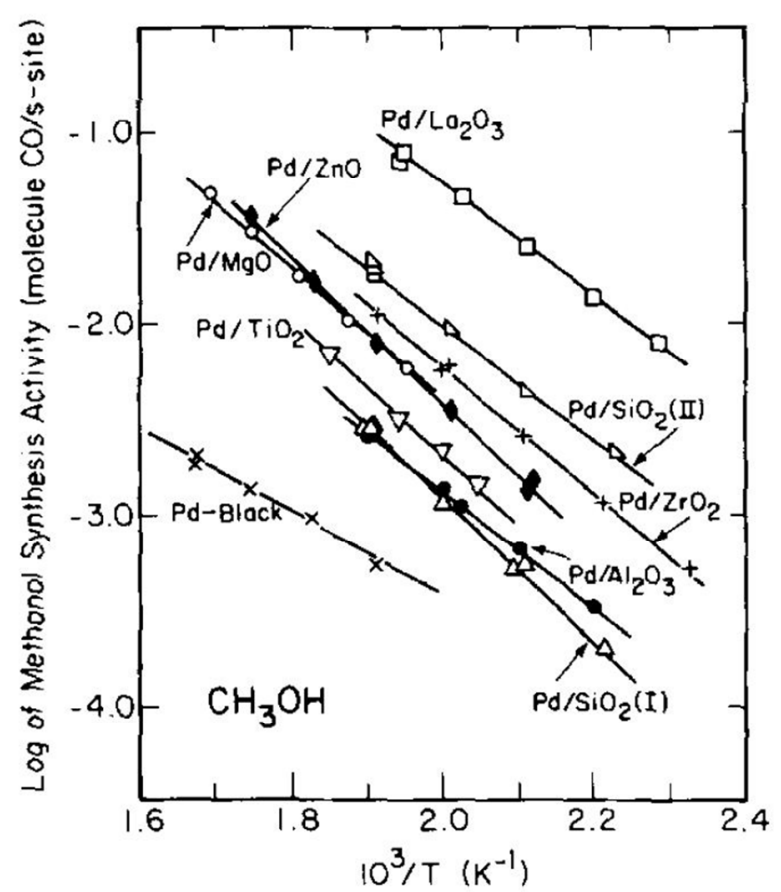

Figure 7. Arrhenius plots for the formation of methanol at $10 \mathrm{~atm}$ and a $\mathrm{H}_{2} / \mathrm{CO}$ ratio of 3 . ${ }^{69}$

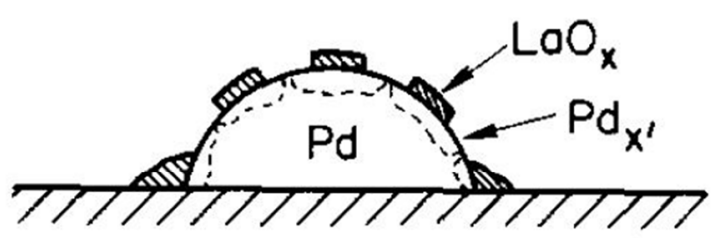

$\mathrm{La}(\mathrm{OH})_{3}, \mathrm{LaO}(\mathrm{OH}), \mathrm{La}_{2} \mathrm{O}_{3}$

Figure 8. Schematic illustration of the interaction of the Pd with the support. ${ }^{44}$

Bell's extensive work on carbon monoxide hydrogenation over supported metal catalysts reveals the true richness of catalytic reaction chemistry. ${ }^{72-75}$ It further illustrates the central role played by the catalyst structure on the reaction kinetics. The key to engineering better catalysts lies in the material and gaining molecular-level control over the synthesis of the active sites. This realization naturally led to Alex's pioneering work on zeolites.

\section{Chemistry of Zeolite Synthesis}


Starting in the mid-1980's, Alex collaborated with Clay Radke, advising several students in projects to understand the hydrothermal synthesis of zeolites, with special attention to using the best tools available to gain insight into what governs the structure direction of zeolite and molecular sieve synthesis. The emphasis was on understanding the process at the molecular level, with an eye to learning how to direct and engineer catalyst sites with molecular control.

In one theme, they pursued an understanding of the solution chemistry, especially using high resolution quantitative multinuclear liquid nuclear magnetic resonance spectroscopy to characterize the solution chemistry at play in synthesis of aluminosilicate zeolites such as zeolite Y, of templated highly siliceous zeolites such as ZSM-5 and silicalite, and of molecular sieves of more varied composition. e.g., $33,76-90^{-10}$

In another theme, they also used solid state magic angle spinning (MAS) NMR to gain understanding of the gel and nucleation processes. One series of papers addressed the role of seed gels in governing the structure of template-free aluminosilicate zeolite synthesis, such as is typical for zeolite $Y{ }^{91-93}$ In another series of papers, they pursued more particularly an understanding of the role of a template cation in directing the crystallization of silica-rich zeolites. $^{87,94-97}$

Characteristically, Alex punctuated with a few periodic papers that give an update on the current thinking, reviewing how patterns and insights can be perceived from contributions from both his own and others groups to frame the next set of broad questions. We can take the opportunity with the series on silicalite to obtain a glimpse of how Alex approached this field and left a lasting impact. In the following, short excerpts from the papers illustrate how the problem - how zeolite nucleation and structure control is achieved - was clearly framed early on, 
attacked methodically, and after rigorous investigations brought to a new level of understanding and design challenges.

Starting in 1991, with Clarence Chang ${ }^{98}$ (then visiting professor from Mobil Research and Development, and a leading figure in templated-zeolite synthesis) Alex examined the then extent data, and new data, of ZSM-5 synthesis carefully to postulate more clearly than anyone how templates might work. They stated that "embryonic structures are formed rapidly with heating", which may have the stoichiometry associated with a template cation surrounded by the intersection structure (Figure 9) - about 1 tetrapropylammonium ion (TPA) to 24 silicons - in a clathrate structure. These structures could be

"randomly lined together, but in time become ordered or "annealed" through repeated cleavage and recombination of the siloxane bonds, mediated by the $\mathrm{OH}$ - ion" (Figure 9). This clear, detailed, and testable hypothesis added structure to the discussion in the literature at the time, postulated by early leaders in the field such as Breck and Flanigen (nicely reviewed by Flanigen 99 ); the basis of the hypothesis is that "the isomorphism between clathrate hydrates and certain framework silicates is exemplary". Further, though, Alex and Clarence drew this implication - that the richness and variety of templated zeolite structures might be explained and even predicted, since the

"structure of the solvation sphere around the organic template will be influenced by factors other than geometry, such as $\mathrm{pH}$, temperature, ionic strength, inorganic ions, etc. so that the same template may give rise to different zeolites phases under different conditions".

This laid out the challenge of that decade, then, in this field - to better understand and predict the action of the template. 




Figure 9. Illustration of clathrate organization around a template cation. ${ }^{98}$

Alex pursued this challenge, seeking a rigorous understanding that could yield quantitative insights into structure direction. Silicalite (the purely siliceous isomorph of ZSM5) provided an excellent model and a rich set of contributions. By 1994, Alex was able to update the current thinking in another contribution, stating "the question is how do organic cations order the silica in zeolite synthesis gels form nuclei for zeolite crystallization". He summarized the findings then current: 
${ }^{، 29}$ Si MAS NMR and ion-exchange experiments of TPA-containing sodium silicate synthesis gels suggest that TPA is encapsulated in the gel in silicate cages prior to the appearance of any crystalline material. Crystallization occurs within the gel via rearrangement of the TPA-occluded silicate cages by the breaking and reformation of siloxane bonds into the more stable silicalite structure".

Alex goes on to show that this understanding is consistent with the then-contemporary contributions from other groups using ${ }^{13} \mathrm{C} \mathrm{NMR},{ }^{1} \mathrm{H}_{-}{ }^{29} \mathrm{Si}$ and ${ }^{1} \mathrm{H}^{-13} \mathrm{C} \mathrm{CP}-\mathrm{MAS}$ NMR, small angle neutron scattering (SANS), and Raman spectroscopy. Further, though, he again draws implications in the most precise terms of the time:

"The evidence also suggests that to form a given zeolite, e.g., ZSM-5, the TAA cation should be as hydrophobic as possible, but not so large as to be unable to fit into the zeolite pore structure in an ordered array."

Even further, he suggests that these questions can and should be pursued with computation. He also later contributed to this computational pursuit as well. ${ }^{96,100,101}$

While encouraging the community along these lines, Alex and Clay made further contributions of their own through the 90's, and Alex took the opportunity once again to give an update on current thinking and prospectus in $1999^{102}$ with a much more specific, quantitative, experimentally tested, and molecularly detailed explanation of all the extent data, suggesting "the following scenario for the nucleation and growth of silicalite. The initial synthesis gel contains a highly articulated silicate network exhibiting a relatively low connectivity.... Hydrated TPA cations are trapped within pockets of the gel. Upon heating, the silicate network condenses... This accounts for the decrease in the triconnected to tetra-connected site $\}$ ratio and the increase in $\mathrm{pH}$ of the mother liquor 
during the induction period. As the gel condenses, it becomes more hydrophobic and expels the water pockets along with the dissolved cations, accounting for the rise in the $\mathrm{Si} / \mathrm{TPA}$ ratio in the solids. As the gel condenses further and its connectivity increases (Figure 10), the hydrophobic TPA cations are engulfed by the silica network, thus forming a cage around the TPA cation. In basic solutions, silica has a net negative charge, thus attracting the TPA cations by Coulombic forces. Occlusion of TPA in the silicate cages competes with the expulsion of solvated TPA contained within the water pockets in the gel. At the onset of crystallization, TPA occlusion dominates over the expulsion of solvated TPA, and as a consequence the Si/TPA ratio of the solid phase of the gel decreases."

- ultimately reaching the stoichiometric value explained with Clarence Chang back in 1991. Figure 11 shows one of the key experiments - quantitative ${ }^{29}$ Si MAS NMR demonstrating a distinct shift in connectivity of the network that marks the induction period. Reflecting on this excerpt a bit, we see Alex's characteristic precision in cleaning up what had been a complicated and murky process description, accounting carefully for the implications from his own work as well as others' work. Each point in this carefully constructed explanation is backed up by datamuch of it collected by Alex, Clay, and students following Alex' formulation of the challenges in 1991 and 1994. 


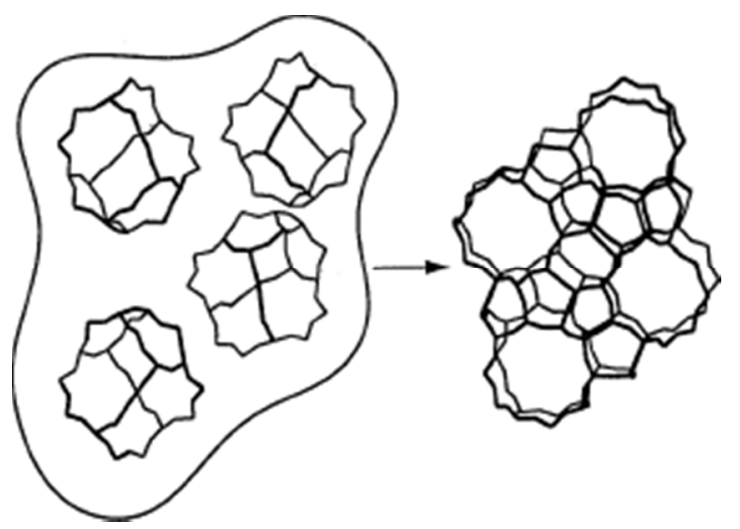

Figure 10. Assembly of clathrates into a prospective nucleus. ${ }^{98}$

In that same review, Alex also was able to show patterns that clarified the current thinking of how aluminosilicates interact with templates to nucleate aluminum containing zeolites; the recent finding from both MAS and liquid NMR showed that the "aluminate anions appear to react with small silicate anions to produce aluminosilicate anions and cause a depolymerization of high molecular weight silicate structures”. This crucial insight helped explain how Al containing systems could manage to participate in the templating process described with the purely siliceous system. Alex and Clay also went on to further important contributions to address the solution behavior of an even richer variety of inorganic ion precursors and templates.

This vignette shows again how Alex worked in collaboration to formulate and attack key problems in a field of importance (here, zeolite synthesis work), driving toward advancing the current state of understanding using both his own and others' insights, and to periodically provide a clear exposition of the next challenging set of questions for the whole community to address. 


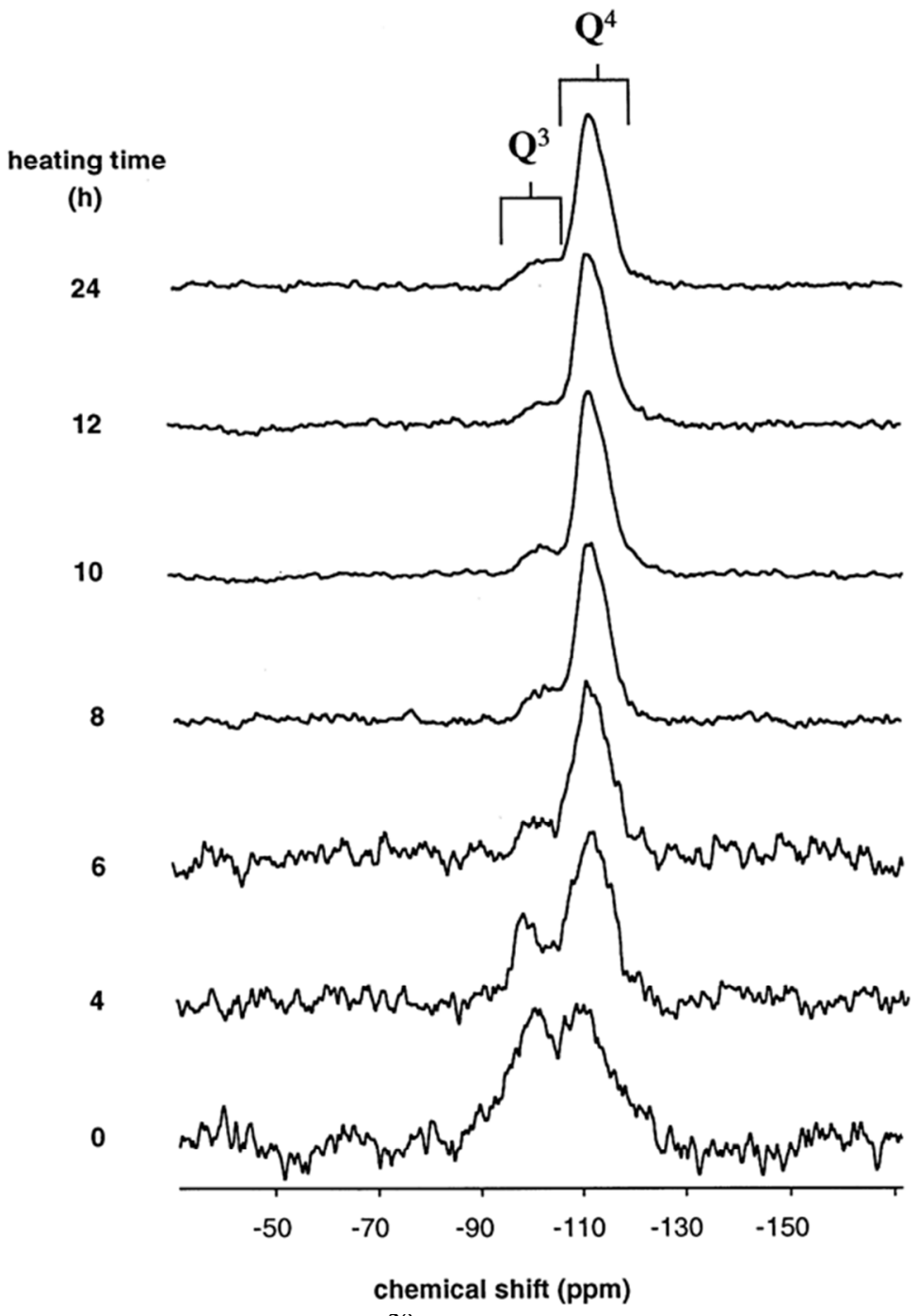

Figure 11. Quantitative ${ }^{29}$ Si MAS NMR patterns, offering key evidence pointing toward a comprehensive description of the silicalite synthesis induction period. ${ }^{102}$

\section{Oxidation Catalysis on Metal Oxides}

One is hard pressed to find either a catalytic moiety or a catalytic reaction that Alex has not touched. Still, certain thematic trends reappear more often than others. One particular family of catalytic materials that have yielded productive investigation spanning four decades has been supported vanadates, ${ }^{39,40,103-129}$ including collaboration with Enrique Iglesia to investigate the kinetics and mechanism for oxidative dehydrogenation of propane, and collaboration with T. Don Tilley to develop techniques for better control of deposition and anchoring of isolated 
vanadates on metal oxide surfaces. The ability to generate catalytically active sites with structural uniformity using isolated vanadates that developed from these studies allowed Alex to expand his effort in the area of "single-site heterogeneous catalysis" as applied to the oxidation of methanol to formaldehyde. ${ }^{130-140}$

Alex writes "A central objective in the field of catalysis is to establish relationships between the composition and structure of catalytically active centers and their activity and selectivity. ${ }^{130}$ For most heterogeneous catalysts, this is a difficult task because of the heterogeneity of active sites, making it nearly impossible to determine the environment of an active site uniquely." By exploiting the ability to anchor isolated $\mathrm{VO}_{4}$ units onto the surfaces of several metal oxide supports, Alex was able to pursue this objective of uniquely tying structure and activity in a series of papers from the mid-2000s to the early 2010s that demonstrates his careful and meticulously thorough approach to mechanistic work. By this time, Alex was able to unleash the full capabilities of his now-mature techniques in in situ FTIR, Raman, and X-ray absorption near edge spectroscopy (XANES) along with density functional theory (DFT) calculations to leave no stone unturned in the pursuit of the definitive explanation that ties together disparate data collected by many researchers working in the same area. The resulting collection of papers reads a little like a multiperspective novel, with the reader's attention shifting back and forth between the point-of-view of two narrators, an experimental one and a computational one. And, as with the fiction, the two narrators tell the same story in an overlapping and complementary way.

The story begins on the computational side with an exploration of how $\mathrm{VO}_{4}$ interacts with the metal atoms of the support. ${ }^{141}$ Isolated vanadates consist of a central vanadium atom with a vanadyl oxygen $(\mathrm{V}=\mathrm{O})$ and three oxygens bridging with surface atoms $(\mathrm{V}-\mathrm{O}-\mathrm{M})$. In this paper, 
the computational model included essentially only this basic structure $(\mathrm{OH}$ groups were added to complete the valences of the $\mathrm{M}$ atoms $)$, and varied the support $(\mathrm{M}=\mathrm{Si}, \mathrm{Ti}, \mathrm{Zr})$ to investigate the support effect. It was already established in the experimental literature that the activity of supported vanadates decreased in the order $\mathrm{ZrO}_{2}>\mathrm{TiO}_{2}>\mathrm{SiO}_{2}$, though the reason for this order was not established. While these early calculations did not reproduce the experimental results quantitatively, they also failed to show any significant difference in either the apparent activation energy or the pre-exponential factor for methanol oxidation over the different supports. This paper concluded that the electronic properties of the metal in the support could not explain the effects seen in the experiments, as they would have surely been apparent in the calculations. The results also suggested that methanol adsorption formed $\mathrm{V}-\mathrm{O}-\mathrm{CH}_{3}$ and $\mathrm{M}-\mathrm{O}-\mathrm{H}$ groups as they were predicted to be much more stable than the reverse of $\mathrm{M}-\mathrm{O}-\mathrm{CH}_{3}$ and $\mathrm{V}-\mathrm{O}-\mathrm{H}$, but again negated any contribution of $\mathrm{M}$ in differentiating between supports.

These results created a puzzle - why did the supports show activity differences in experiments but were nearly indistinguishable computationally? Alex would spend eight years building a systematic case to explain these observations, but the original conclusions of his first and simplest exploration of the subject were never refuted by his later work.

Next, Alex set out to establish the definitive mechanism for methanol oxidation over vanadate on silica (MCM-48). ${ }^{130}$ Through a series of carefully planned in situ temperature programmed spectroscopic experiments, the population of adsorbed and surface species were tied to the gaseous products. Every bit of data in the paper supports the final conclusion, and the paper is a great example of Alex's 'leave no stone unturned' approach. Every possible surface interaction is tested and every competing theory is discussed. In the end, the totality of the FTIR, Raman, XANES and kinetic measurements leads to a single mechanism. Importantly, this paper 
provides direct observation that proton transfer from methoxide to the vanadyl oxygen is the rate-limiting step - as suggested by earlier computational work. At the close of this experimental chapter, the evidence is summarized in two mechanistic schemes for the temperature programmed desorption (TPD) and temperature programmed oxidation (TPO) experiments that show the flux of each species and proposed intermediate (Figures 12 and 13). But these experiments were only able to observe the oxidation of methanol, which necessarily must have resulted in reduced vanadium centers that were not observed. Alex concluded that the reoxidation must have been fast, but no mechanism was known.

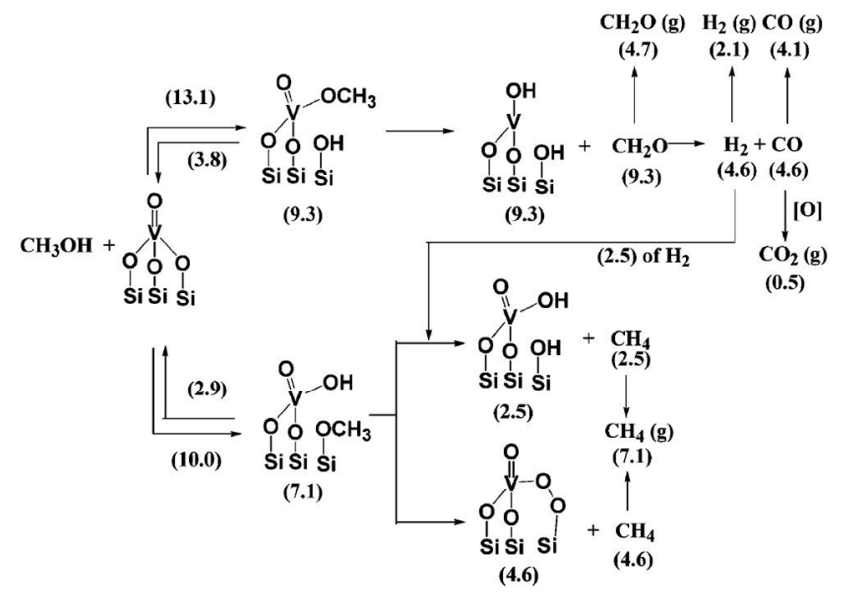

Figure 12. Mechanistic scheme for the TPD experiment on 3.4V/MCM-48. ${ }^{130}$

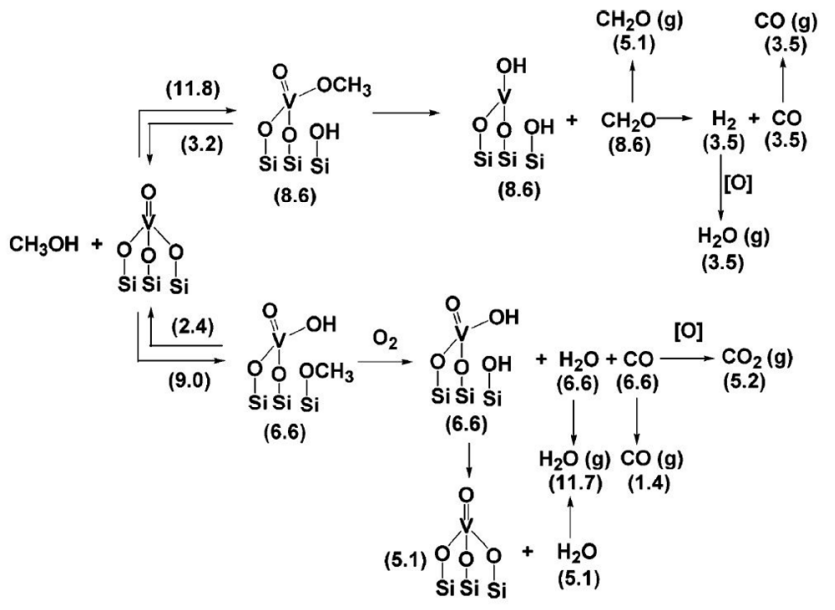

Figure 13. Mechanistic scheme for the TPO experiment on 3.4V/MCM-48. ${ }^{130}$ 
Naturally, the next paper in the series was about the reoxidation of the vanadium. If a process is too fast to observe experimentally, it is best approached computationally. An update to the support model for $\mathrm{SiO}_{2}$ involved using a silsesquioxane molecule, with one $\mathrm{Si}$-atom vertex replaced by $\mathrm{V}=\mathrm{O}$ (Figure 14). ${ }^{131}$ With DFT, Alex was able to probe every step in the methanol oxidation/vandadium reduction mechanism and show that it matched the experimental results, but also add the missing details about the vanadium reoxidation mechanism. Once again, Alex's intuition proved correct, and the reoxidation of $\mathrm{V}^{3+}$ to $\mathrm{V}^{5+}$ was facile as compared to the methanol oxidation step, explaining why $\mathrm{V}^{3+}$ species were never observed. In the process, the paper touches upon every possible mechanism along the way, so as to eliminate the infeasible ones with evidence. Here also the reoxidation mechanism was established. The issue is that each molecule of dioxygen should oxidize two reduced vanadium centers, but the vanadium atoms are isolated from one another. The solution is to have molecular oxygen adsorb to the $\mathrm{V}^{3+}$, creating a peroxo group that will propagate an oxygen atom through the support $\mathrm{Si}-\mathrm{O}-\mathrm{Si}$ bonds until it reaches another reduced $\mathrm{V}^{3+}$ center. The notion that oxygen atoms could travel through silica was counterintuitive, but was supported by both earlier work over isolated molybdates on silica $^{142}$ and, of course, by Alex's own follow up paper, ${ }^{133}$ where he showed the same isotopic scrambling using ${ }^{18} \mathrm{O}_{2}$ over isolated vanadates on silica. 

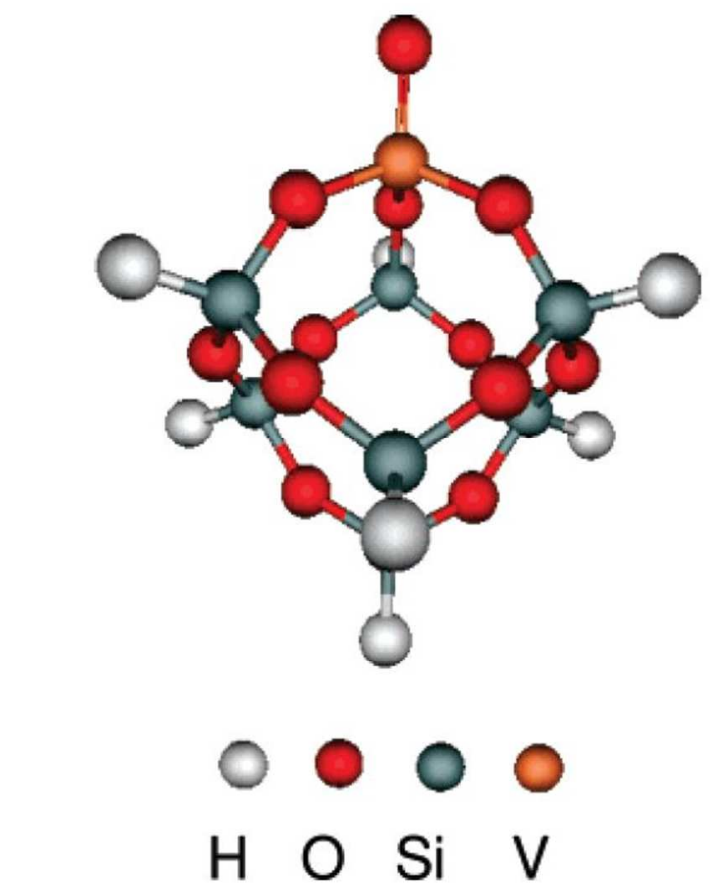

Figure 14. Model of the $\mathrm{VO}_{\mathrm{x}} / \mathrm{SiO}_{2}$ catalytic site. ${ }^{131}$
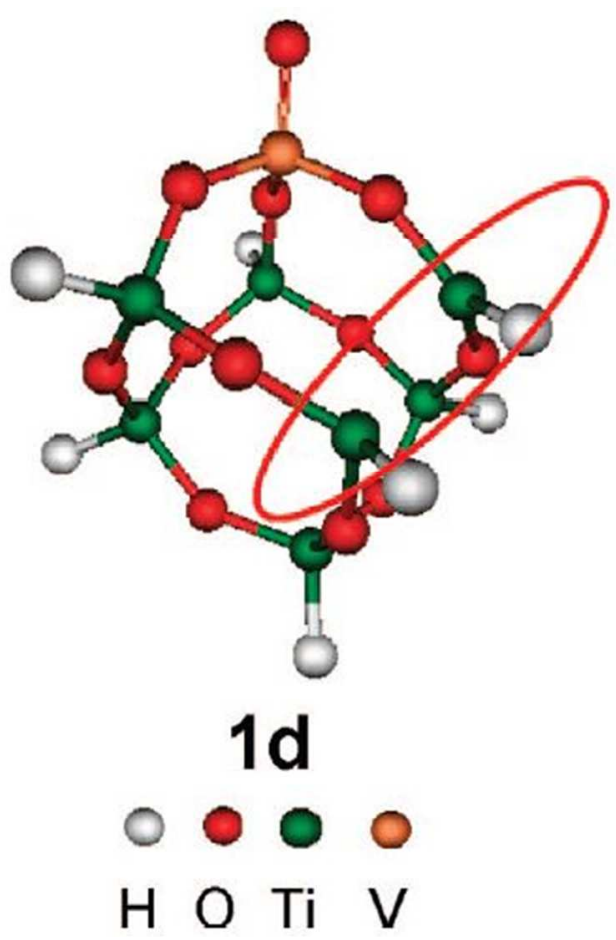

Figure 15. Model of the $\mathrm{VO}_{\mathrm{x}} / \mathrm{TiO}_{2}$ catalytic site. The location of the O-vacancy is circled. ${ }^{135}$ 
Common threads found throughout Alex's work and exemplified in these papers are his ability to anticipate questions and criticisms and provide responses in the same papers, and his ability to predict correctly the findings of future papers in the same series.

Having conquered the mechanism of methanol oxidation on $\mathrm{VO}_{4} / \mathrm{SiO}_{2}$, the next logical step was to understand why $\mathrm{SiO}_{2}$ was such a poor support and why $\mathrm{TiO}_{2}{ }^{132}$ and $\mathrm{ZrO}_{2}{ }^{136}$ were three orders of magnitude higher in activity under the same conditions. The reactivity of these supports is very different from silica, but how exactly does that make the methanol oxidation reaction faster? When all three supports were treated as structurally the same ${ }^{141}$ calculations suggested that the apparent activation energies for methanol oxidation would all fall between 112 and $123 \mathrm{~kJ} \mathrm{~mol}^{-1}$. But the experiments showed that only $\mathrm{SiO}_{2}\left(96 \mathrm{~kJ} \mathrm{~mol}^{-1}\right)$ was even close, with $\mathrm{TiO}_{2}\left(67 \mathrm{~kJ} \mathrm{~mol}^{-1}\right)$ and $\mathrm{ZrO}_{2}\left(75 \mathrm{~kJ} \mathrm{~mol}^{-1}\right)$ quite a bit lower.

First, the experimental work ruled out all other possible explanations, and together with the computations, suggested that these surfaces are not structurally interchangeable. Of course, Alex had a hypothesis, which he then followed up with a new computational study that explored the role of oxygen vacancy defects on the activity for methane oxidation (Figure 15). ${ }^{135}$ As it turns out, the oxygen vacancies typically encountered on $\mathrm{TiO}_{2}$ surfaces, when located adjacent to a V-O-Ti bond, "provides the active site with more flexibility thereby allowing for a larger degree of $\mathrm{H}$-bonding in the $\left[\mathrm{V}-\mathrm{O}-\mathrm{CH}_{3}\right.$ dehydrogenation] product between $\mathrm{Ti}-\mathrm{OH}$ and $\mathrm{V}-\mathrm{OH}$ ligands." The oxidation state and environment of vanadium are not changed, hence no differences in the XANES or Raman spectra between $\mathrm{SiO}_{2}$ and $\mathrm{TiO}_{2}$ are observed. The surface species involved are the same, hence no change in the FTIR spectra either. Such a puzzle as support effects between $\mathrm{SiO}_{2}$ and $\mathrm{TiO}_{2}$ came down to a small difference in the flexibility of the bonding in the support backbone, leading to stronger hydrogen bonding. This small difference 
had a big impact on the results. The stabilization of the transition state in the rate-limiting step lowered the calculated apparent activation energy to $66.5 \mathrm{~kJ} \mathrm{~mol}^{-1}$, in excellent agreement with the experiment. To engineer this observation into a new catalyst, Alex later followed up this work with computational and experimental investigations of bilayered $\mathrm{VO}_{\mathrm{x}} / \mathrm{MO}_{\mathrm{x}} / \mathrm{SiO}_{2}$ materials with defect forming metal oxides $(\mathrm{M}=\mathrm{Ti}, \mathrm{Zr}, \mathrm{Ce}) .{ }^{137-139}$

The story here developed from the ability to characterize the mechanism at single site catalysts, and under Alex's watch revealed how structural flexibility in defective metal oxides enhances transition state stabilization, and how new classes of catalysts could be developed to exploit these properties.

\begin{abstract}
Alex in Theory
From the end of the 1980s on, Bell's work gradually includes more computational, quantum and statistical mechanical simulations to complement experimental work. As computers became more powerful, this was not a digression, but a natural expansion to achieve his overall objective to understand those fundamental underpinnings of catalysis that could be translated to the context of practical applications, for the purpose of catalyst development and design.

His views are nicely outlined in a short perspective article in $1990^{75}$ on the "impact of catalyst science on catalyst design and development," which is still relevant. Paraphrasing Bell, this impact results from: (1) the pursuit of scientific understanding, which continues to lead to the development of new analytical techniques, helping to reduce the time and options to evaluate catalysts by testing; (2) molecular level views (one could now add "nano"-level views, as in his perspective in Science in 2003), ${ }^{143}$ to guide catalyst formulations; (3) development of new theories and concepts, to achieve relationships between catalyst structure and performance. This scientific approach reduces empiricism in development, and, increasingly, design.
\end{abstract}


The chemical engineer in Bell is once again clear from his choice of reactions that are of particular, timely industrial significance, in particular in the energy and environmental arena, such as removal of NO, methanol or Fisher-Tropsch synthesis. Here, he attempts to obtain information under conditions that are relevant to industrial catalysis. For the same reasons, in situ spectroscopy is used to unravel reaction mechanisms and understand the structural and compositional changes that occur in heterogeneous catalysts, in mixtures, under reaction conditions. There is a preference for in situ IR and Raman, but also NMR and isotopic tracer studies, to probe species over time, on different surfaces that aim to best represent the industrial catalyst, or a model that would help to unravel pertinent principles.

Alex Bell avidly collaborates with other chemical engineers and chemists at UC Berkeley and LBNL, as well as internationally, to build on complementary expertise. These key collaborations signal new directions, or help to obtain the missing piece in the catalytic puzzle.

Alex' theoretical work began in the late 1980s with Evgeny Shustorovich from Eastman Kodak in Rochester. They used the bond-order-conservation-Morse-potential method (BOC MP) ${ }^{74,144-151}$ to account for molecule-surface and intermolecular interactions at realistic loadings, in order to study adsorption, surface diffusion and desorption by, for example, Monte-Carlo techniques. In conjunction with the papers with Lombardo over the same period, ${ }^{64,103,152-154}$ theoretical models appeared that would help to describe kinetics of gases on metal and other surfaces. Importantly, results from these models could be tested against TPD and other experimental methods. The 1991 review by Lombardo and Bell in Surf. Sci. Rep. ${ }^{154}$ signaled a new era in which various types of Monte-Carlo simulations, molecular dynamics, transition-state theory, and other statistical physical as well as quantum mechanical approaches would 
increasingly play a central role in studying diffusion, adsorption and reaction in catalysts, in particular zeolites.

The second stage of Alex' computational work, a notable collaboration with Doros Theodorou, lasted throughout the 1990s. They developed powerful Monte Carlo tools for understanding adsorption and diffusion of molecules in zeolites. ${ }^{155-157}$ Alex and Doros showed how tools from statistical physics could predict how molecules arrange themselves and navigate the nanoscale pores within zeolites (Figure 16). In the process, they cultivated students who would put their own mark on this new branch of catalysis research: June, ${ }^{158-162}$ Snurr, ${ }^{161,163-166}$ Maginn, ${ }^{167-169}$ and Coppens. ${ }^{170-172}$

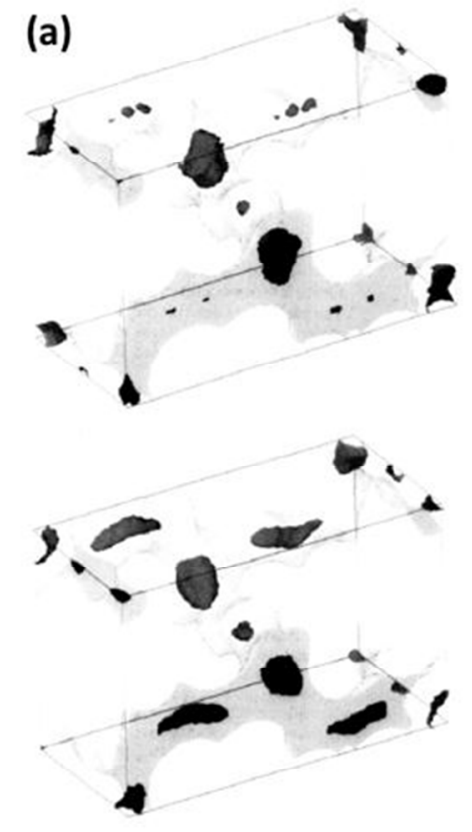

(b)

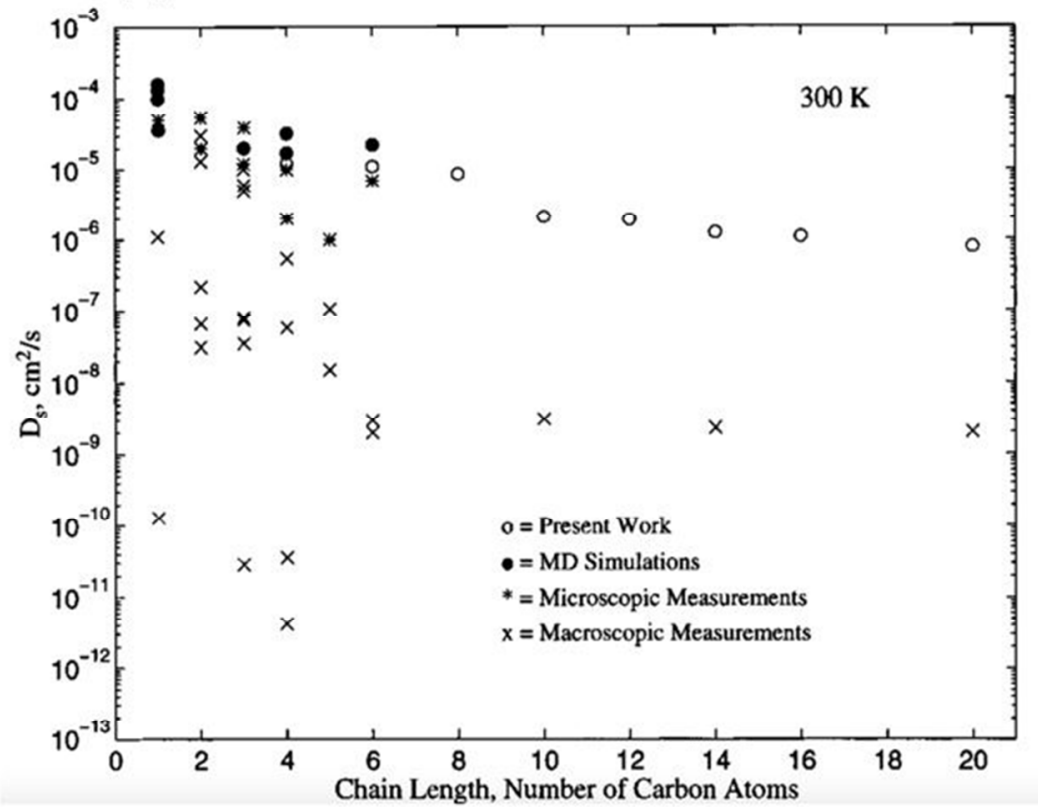

Figure 16. (a) Location of benzene molecules adsorbed in the pore space of silicalite- 1 at $70^{\circ} \mathrm{C}$, illustrating clearly defined sites in the pore space (dark regions: 95\% probability), but also differences at low (top) and high loading (bottom). ${ }^{165}$ (b) Self-diffusivity of n-alkanes as a function of chain length, at $300 \mathrm{~K}$, comparing molecular dynamics and hierarchical simulations with experiments. The simulation strategy utilizes concepts from Brownian motion theory and transition state theory. ${ }^{169}$ 
The overarching finding from this work is that adsorption and transport within zeolites is influenced by subtle heterogeneities in structure and composition and by the correlations between adsorbate molecules at high loadings. These effects are not well captured by mean-field models. Elsewhere in the catalysis world, van Santen, Sauer, Catlow and others were also finding that Langmuir-Hinshelwood expressions and other mean-field relationships do not adequately account for the local environments and interactions between adsorbed species on surfaces. Especially at higher loadings, these local environments differ from the averages, and may not be representative of the conditions relevant to heterogeneous catalysis. In the most extreme cases, as poignantly illustrated by Ertl, deviations from mean field behavior give rise to multiple steady states, transient behavior, and nonlinear waves.

A third stage of Alex' theoretical work began in the mid-1990s, as ab initio computational chemistry was growing in power, accuracy, and accessibility. Alex and his colleague Arup Chakraborty saw an opportunity for catalysis research in new hybrid density functionals and Pople basis sets. They were among the pioneers in using computational chemistry, particularly density functional theory, to study adsorption and reactivity in zeolites. Their work illustrated how these tools could be used to predict binding enthalpies, reaction energies, activation barriers, and to make ab initio spectroscopic assignments. ${ }^{173-177}$

Trout et al. used density functional theory to study the speciation of $\mathrm{Cu}^{+},[\mathrm{CuO}]^{+}$, and $[\mathrm{CuOH}]^{+}$ions $^{173}$ and the thermochemistry of NO decomposition ${ }^{174}$ in a Cu-ZSM-5 catalyst. Rice et al. used DFT to understand the role of water in the demetallation of Cu-ZSM-5 and Co-ZSM5. ${ }^{177}$ In their study of $\mathrm{N}_{2} \mathrm{O}$ decomposition by Fe-ZSM-5 and Co-ZSM-5, Ryder et al. showed how $a b$ initio calculations of rate constants and equilibrium constants can facilitate the construction of microkinetic models and the interpretation of experimental activation barriers. ${ }^{178}$ 
In these early computational studies, the number of intermediates and elementary steps was limited by the difficulty of the electronic structure calculations and transition state optimizations.

Alex' early computational studies, using tools from both molecular simulation and quantum chemistry, gave him a unique perspective on the challenges ahead. His 2004 review article, "Challenges for the application of quantum chemical calculations to problems in catalysis", ${ }^{179}$ identified four main challenges for the future. This review article marks the beginning of a fourth stage in Alex' theoretical/computational work. The method development challenges identified in Alex' article became a to-do list, not just for Alex, but also for the computational catalysis efforts of many others. His method development goals and contributions toward achieving them include:

(1) Accurate rate expressions for the elementary steps in catalysis.

Alex has shown that recrossing corrections to transition state theory are usually negligible in catalysis, ${ }^{180}$ but tunnelling ${ }^{181}$ and curve-crossing (non-adiabatic) rates can be important. $^{136}$ He has also shown that non-equilibrium dynamics determine product selectivity in acid (zeolite) catalysed cracking reactions. ${ }^{182,183}$

(2) Accurate models of active sites and adsorbate interactions in zeolites.

Alex' early work used constrained cluster models for zeolites, ${ }^{175,177,184}$ but his more recent work used larger models with state-of-the-art quantum chemistry and importance sampling methods. Their efforts resulted in benchmark studies of hydrocarbon adsorption that include electrostatics and dispersion through QM/MM embedding schemes, ${ }^{185}$ and re-optimized classical force fields for modelling alkanes in zeolites. ${ }^{186,187}$

(3) Efficient, automated methods for discovering reaction pathways and intermediates. In collaboration with Arup Chakraborty and Frerich Keil, Alex developed new transition 
state search algorithms with improved efficiency, ${ }^{188-194}$ improved fault tolerance, ${ }^{195}$ biases to avoid rediscovery, ${ }^{196}$ and automated path generation capabilities ${ }^{197}$ to reduce reliance on human effort and intuition. Some of these tools are now state-of-the-art algorithms for discovering transition states and intermediates in complex reaction networks.

The above methodological advances from Alex' own research group and also from others enabled studies of vastly more complex catalytic reaction networks and processes. In a series of computational papers published between 2005 and 2008, Alex revisited his earlier studies of $\mathrm{N}_{2} \mathrm{O}$ and NO decomposition by Fe-ZSM-5. The works by Heyden et al. ${ }^{198,199}$ and Hansen et al. ${ }^{200}$ expanded the $\mathrm{NO}_{\mathrm{x}}$ reduction mechanisms to include hundreds of elementary reactions at monoand bi-nuclear Fe sites. Their ab initio calculations and kinetic models explain the effects of temperature, humidity, oxygen, and iron loading on the NOx reduction activity of Fe-ZSM$5^{175,201}$

An elegant series of computational studies from Alex' group examined hydrocarbon cracking by acid zeolites. The overall cracking mechanism involves three steps: adsorption of alkanes into the zeolite framework, association with an acid site, and the catalytic protonolysis steps. Catalytic cracking, as Alex surely anticipated, was ideal for computational analysis: industrially important, simple enough to permit comprehensive calculations, and sufficiently complex to present unresolved questions. At the time of their computational studies, the overall activation energy was known to depend on chain length primarily because of the adsorption step. Alex, working with Berend Smit and Martin Head-Gordon, extended our understanding to the more subtle effects of entropy, zeolite structure, and reaction dynamics. ${ }^{182,202,203}$ The analysis by Swisher et al. is a blueprint for rigorous and thorough computational work. ${ }^{204}$ They used 
configurational bias Monte Carlo simulations to compute the adsorption enthalpy and entropy at reaction conditions for various alkanes, in various sites, and in several different zeolites. They combined the computed adsorption enthalpies and entropies with overall activation parameters from experiment to obtain activation enthalpy and entropy estimates for the catalytic steps (see Figure 17). Swisher et al. also used DFT to predict rates for the chemical step. ${ }^{204}$ Computed and measured overall rates (for the FAU zeolite) agreed within a factor of about 100 from propane to n-hexane. Later calculations by Sharada et $a l .{ }^{205}$ and Janda et $a l .^{204}$ improved the calculations with better DFT calculations and better zeolite models.
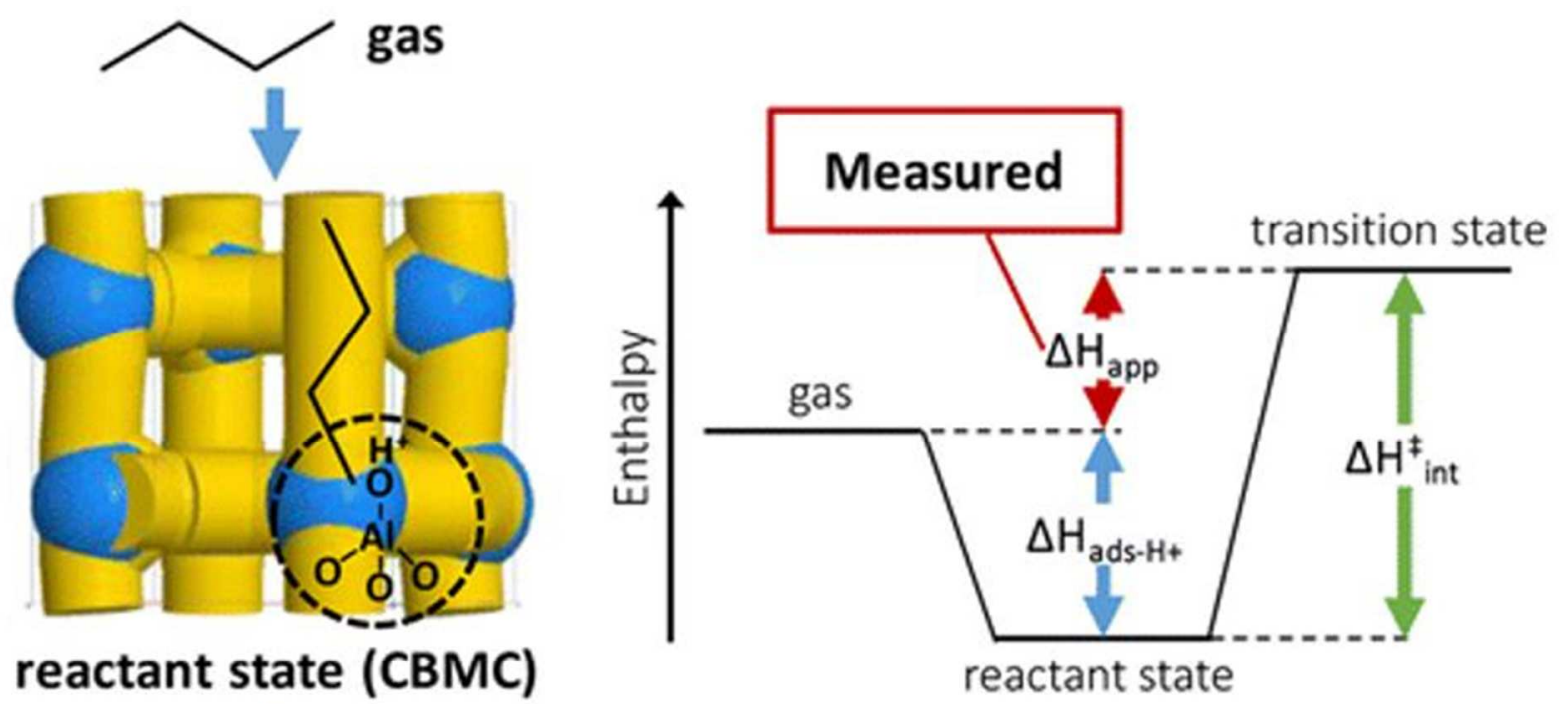

\section{transition state (QM/MM)}

Figure 17. Combined adsorption enthalpies and entropies from Monte Carlo simulations (blue) with overall activation parameters from experiment (red) to infer activation parameters for the chemical step (green). An independent confirmation of the overall cracking mechanism can then be obtained by using DFT calculations for the elementary cracking step(s). ${ }^{202}$

\section{Alex in Practice}

This methodical approach reveals the long-term, systematic thinking of Alex Bell as a scientist. Patient development of new computational and experimental tools, applying them step 
by step to pertinent problems in structured catalysts, allow him to, over time, construct a more and more complete picture of the problem at hand, solving outstanding questions that lead from science, to development, and to design, as outlined in Reference 75.

One thing that stands out when reading Alex Bell's published work is his exceptional writing skill. Both in original journal articles and in perspective articles and reviews, his writing is clear and concise, with well-chosen words and easy sentences. The presentation of the scientific story is well crafted from Abstract through to Conclusions. The main findings, as well as the motivation for the work jump right off the page, supported by clear scientific arguments, and illustrated by the perfect number of tables and figures. Alex devoted much of his time teaching scientific writing to his graduate students. All of them benefited greatly from his mentorship, and throughout their careers employed to advantage the writing and oral skills learned from Professor Bell.

As a former postdoctoral researcher during the time that Bell was Dean of the College of Chemistry at UC Berkeley, one of the authors (Marc-Olivier Coppens) was struck by the way in which work for the College and research time would be perfectly separated, in space (different offices) and time (regular appointments). In this, he was as systematic as the way in which he would conduct his research. For example, on any Wednesday, Alex Bell would have research appointments in his Departmental office during the morning (Marc-Olivier's were at 10am), then move to the Dean's Office for the afternoon, and typically make a round in the evening, where he would sometimes drop into the office for an extra conversation. Alex Bell was always poised, well organised and prepared; he listened carefully and asked excellent questions, leading to effective discussions. This made a great impact on Marc-Olivier for organizing his work later on 
in his career, especially in combining his current positions as Head of Department, Centre Director, scientific research and time for teaching and students.

Those who haven't worked with Alex may wonder how anyone can have such tremendous breadth, but anyone who has written a paper with him has seen the recipe. When Alex sits down with collaborators or students to revise a manuscript, he isn't just there to finish the paper. He wants to assimilate and master the full skillset of his co-author. In the familiar parts of a manuscript, he asks razor sharp questions about wording and internal consistency. But when he encounters a part of the manuscript with ideas, principles, or methods that are new, he asks different types of questions. He wants to know in full detail how it works and how it relates to what he already knows. He is a fast study. After one long meeting, Alex can not only use the new ideas but he can give an impromptu lesson to the next student.

As a PhD advisor, Alex is a fountain of refreshing, child-like enthusiasm. He typically arrives a few minutes late to meetings with his $\mathrm{PhD}$ students (we called it Berkeley time). He hustles in with an excited grin, wringing his hands as though he was next up to bat, and then dives right into the technical discussion. His excitement over new results was a wonderful source of motivation.

\section{Summary}

We have enjoyed putting together even this modest number of vignettes to help celebrate Alex's contributions to catalysis and reaction engineering - both as a technical field and as a scholarly community. At the occasion of his $70^{\text {th }}$ birthday celebration in Berkeley Alex commented that he was drawn to Berkeley because John Prausnitz told him on a visit that 'here students do not work for us, we collaborate with them'. He did just that - collaborate with his students and postdoctoral fellows. 


\section{Supporting Information}

The Supporting Information is available free of charge on the ACS Publications website at DOI:Xxxxxxxxxxxx.

A list of Alex Bell's publications (PDF).

\section{References}

1. Bell, A. T. Industrial \& Engineering Chemistry Fundamentals 1970, 9, 679-681.

2. Bell, A. T. Industrial \& Engineering Chemistry Fundamentals 1972, 11, 209-215.

3. Bell, A. T.; Kwong, K. Industrial \& Engineering Chemistry Fundamentals 1973, 12, 9094.

4. Kobayashi, H.; Bell, A. T.; Shen, M. Macromolecules 1974, 7, 277-283.

5. Bell A.T. Fundamentals of Plasma Chemistry. In Techniques \& Applications of Plasma Chemistry; Hollahan J. R., Bell A. T., Eds.; Wiley, New York, 1974.

6. Tibbitt, J. M.; Shen, M.; Bell, A. T. Thin Solid Films 1975, 29, L43-L45.

7. Bell, A. T. Journal of Macromolecular Science: Part A - Chemistry 1976, 10, 369-381.

8. Tibbitt, J. M.; Jensen, R.; Bell, A. T.; Shen, M. Macromolecules 1977, 10, 647-653.

9. Nakajima, K.; Bell, A. T.; Shen, M.; Millard, M. M. Journal of Applied Polymer Science 1979, 23, 2627-2637.

10. Bell, A. T. Journal of Vacuum Science and Technology 1979, 16, 418-419.

11. London, J. W.; Bell, A. T. Journal of Catalysis 1973, 31, 96-109.

12. London, J. W.; Bell, A. T. Journal of Catalysis 1973, 31, 32-40.

13. Low, G. G.; Bell, A. T. Journal of Catalysis 1979, 57, 397-405.

14. Ekerdt, J. G.; Bell, A. T. Journal of Catalysis 1979, 58, 170-187.

15. Ekerdt, J. G.; Bell, A. T. Journal of Catalysis 1980, 62, 19-25.

16. Kellner, C. S.; Bell, A. T. Journal of Catalysis 1981, 67, 175-185. 
17. Bell, A. T. Catalysis Reviews 1981, 23, 203-232.

18. Kellner, C. S.; Bell, A. T. Journal of Catalysis 1981, 70, 418-432.

19. Lorimer, D. A.; Bell, A. T. Journal of Catalysis 1979, 59, 223-238.

20. Vibrational Spectroscopies for Adsorbed Species; Bell A.T., Hair M.L., Eds.; American Chemical Society: Washington D.C., 1980.

21. Bell, A. T. Applications of Fourier Transform Infrared Spectroscopy to Studies of Adsorbed Species. In Vibrational Spectroscopies for Adsorbed Species; Bell A.T., Hair M.L., Eds.; American Chemical Society: Washington D.C., 1980; Vol. 137, pp 13-35.

22. Kellner, C. S.; Bell, A. T. Journal of Catalysis 1981, 71, 296-307.

23. Hecker, W. C.; Bell, A. T. Journal of Catalysis 1983, 84, 200-215.

24. Hecker, W. C.; Bell, A. T. Journal of Catalysis 1984, 85, 389-397.

25. Bell A. T. Fourier-Transform Infrared Spectroscopy in Heterogeneous Catalysis. In Chemistry and Physics of Solid Surfaces V; Vanselaw R., Howe R., Eds.; Springer-Verlag: Berlin, 1984.

26. Hicks, R. F.; Kellner, C. S.; Savatsky, B. J.; Hecker, W. C.; Bell, A. T. Journal of Catalysis 1981, 71, 216-218.

27. Winslow, P.; Bell, A. T. Journal of Catalysis 1984, 86, 158-172.

28. Tejuca, L. G.; Bell, A. T.; Cortés Corberán, V. Applied Surface Science 1989, 37, 353366.

29. Duncan, T. M.; Winslow, P.; Bell, A. T. Chemical Physics Letters 1983, 102, 163-167.

30. Chan, S. S.; Bell, A. T. Journal of Catalysis 1984, 89, 433-441.

31. Duncan, T. M.; Winslow, P.; Bell, A. T. Journal of Catalysis 1985, 93, 1-22. 
32. Duncan, T. M.; Reimer, J. A.; Winslow, P.; Bell, A. T. Journal of Catalysis 1985, 95, 305308.

33. Bell, A. T.; McCormick, A. V.; Hendricks, W. M.; Radke, C. J. Chemistry Express 1986, $1,687-689$.

34. Reichmann, M. G.; Bell, A. T. Langmuir 1987, 3, 111-116.

35. Haddix, G. W.; Reimer, J. A.; Bell, A. T. Journal of Catalysis 1987, 106, 111-115.

36. Reichmann, M. G.; Bell, A. T. Langmuir 1987, 3, 563-567.

37. Haddix, G. W.; Reimer, J. A.; Bell, A. T. Journal of Catalysis 1987, 108, 50-54.

38. Haddix, G. W.; Bell, A. T.; Reimer, J. A. Catalysis Letters 1988, 1, 207-212.

39. Oyama, S. T.; Went, G. T.; Lewis, K. B.; Bell, A. T.; Somorjai, G. A. The Journal of Physical Chemistry 1989, 93, 6786-6790.

40. Went, G. T.; Oyama, S. T.; Bell, A. T. The Journal of Physical Chemistry 1990, 94, 42404246.

41. Kellner, C. S.; Bell, A. T. Journal of Catalysis 1982, 75, 251-261.

42. Arakawa, H.; Bell, A. T. Industrial \& Engineering Chemistry Process Design and Development 1983, 22, 97-103.

43. Fleisch, T. H.; Hicks, R. F.; Bell, A. T. Journal of Catalysis 1984, 87, 398-413.

44. Hicks, R. F.; Yen, Q.-J.; Bell, A. T. Journal of Catalysis 1984, 89, 498-510.

45. Hicks, R. F.; Yen, Q.-J.; Bell, A. T.; Fleisch, T. H. Applications of Surface Science 1984, $19,315-329$.

46. Singh, A. K.; Pande, N. K.; Bell, A. T. Journal of Catalysis 1985, 94, 422-435.

47. Rieck, J. S.; Bell, A. T. Journal of Catalysis 1985, 96, 88-105.

48. Pande, N. K.; Bell, A. T. Applied Catalysis 1986, 20, 109-122. 
49. Dictor, R. A.; Bell, A. T. Applied Catalysis 1986, 20, 145-162.

50. Pande, N. K.; Bell, A. T. Journal of Catalysis 1986, 97, 137-149.

51. Underwood, R. P.; Bell, A. T. Applied Catalysis 1986, 21, 157-168.

52. Pande, N. K.; Bell, A. T. Journal of Catalysis 1986, 98, 7-16.

53. Rieck, J. S.; Bell, A. T. Journal of Catalysis 1986, 99, 262-277.

54. Rieck, J. S.; Bell, A. T. Journal of Catalysis 1986, 99, 278-292.

55. Rieck, J. S.; Bell, A. T. Journal of Catalysis 1986, 100, 305-321.

56. Levin, M. E.; Salmeron, M.; Bell, A. T.; Somorjai, G. A. Journal of Catalysis 1987, 106, 401-409.

57. Underwood, R. P.; Bell, A. T. Journal of Catalysis 1988, 109, 61-75.

58. Satvasky B.J.; Bell A.T. Nitric Oxide Reduction by Hydrogen over Rhodium Using Transient Response Techniques. In Catalysis Under Transient Conditions; Bell A.T., Hegedus L.L., Eds.; American Chemical Society: Washington, D.C. 1982; pp 105-141.

59. Cant, N. W.; Bell, A. T. Journal of Catalysis 1982, 73, 257-271.

60. Rieck, J. S.; Bell, A. T. Journal of Catalysis 1984, 85, 143-153.

61. de Pontes, M.; Yokomizo, G. H.; Bell, A. T. Journal of Catalysis 1987, 104, 147-155.

62. Tejuca, L. G.; Bell, A. T.; Fierro, J. L. G.; Tascon, J. M. D. Journal of the Chemical Society, Faraday Transactions 1: Physical Chemistry in Condensed Phases 1987, 83, 3149-3159.

63. Yokomizo, G. H.; Bell, A. T. Journal of Catalysis 1989, 119, 467-482.

64. Lombardo, S. J.; Bell, A. T. Surface Science 1989, 224, 451-475.

65. Winslow, P.; Bell, A. T. Journal of Catalysis 1985, 94, 385-399.

66. Davydov, A. A.; Bell, A. T. Journal of Catalysis 1977, 49, 332-344. 
67. Davydov, A. A.; Bell, A. T. Journal of Catalysis 1977, 49, 345-355.

68. Kuznetsov, V. L.; Bell, A. T.; Yermakov, Y. I. Journal of Catalysis 1980, 65, 374-389.

69. Ryndin, Y. A.; Hicks, R. F.; Bell, A. T.; Yermakov, Y. I. Journal of Catalysis 1981, 70, 287-297.

70. Baker, J. A.; Bell, A. T. Journal of Catalysis 1982, 78, 165-181.

71. Winslow, P.; Bell, A. T. Journal of Catalysis 1985, 91, 142-154.

72. Bell A.T. Supports and Metal-Support Interactions in Catalyst Design. In Catalyst DesignProgress and Perspectives; Hegedus L.L., Bell A.T., Chen N.Y., Haag W.O., Wei J., Aris R., Boudart M., Gates B.C., and Somorjai G.A., Eds.; Wiley: New York, 1987; pp 103.

73. Bell, A. T. Reaction Kinetics and Catalysis Letters 1987, 35, 107-121.

74. Shustorovich, E.; Bell, A. T. Journal of Catalysis 1988, 113, 341-352.

75. Bell, A. T. Chemical Engineering Science 1990, 45, 2013-2026.

76. McCormick, A. V.; Bell, A. T.; Radke, C. J. Studies in Surface Science and Catalysis $1986,28,247-254$.

77. McCormick, A. V.; Bell, A. T.; Radke, C. J. Zeolites 1987, 7, 183-190.

78. McCormick, A. V.; Bell, A. T.; Radke, C. J. MRS Proceedings 1987, 111.

79. McCormick, A. V.; Bell, A. T.; Radke, C. J. Effect of Alkali Metal Cations on Silicate Structures in Aqueous Solution. In Perspectives in Molecular Sieve Science; American Chemical Society: Washington D.C., 1988; Vol. 368, pp 222-235.

80. McCormick, A. V.; Bell, A. T.; Radke, C. J. MRS Proceedings 1988, 121.

81. McCormick, A. V.; Bell, A. T.; Radke, C. J. The Journal of Physical Chemistry 1989, 93, $1733-1737$. 
82. McCormick, A. V.; Bell, A. T.; Radke, C. J. The Journal of Physical Chemistry 1989, 93, 1737-1741. Erratum, McCormick, A. V.; Bell, A. T.; Radke, C. J. The Journal of Physical Chemistry 1989, 93, 8270-8270.

83. McCormick, A. V.; Bell, A. T.; Radke, C. J. The Journal of Physical Chemistry 1989, 93, $1741-1744$.

84. McCormick, A. V.; Bell, A. T. Catalysis Reviews 1989, 31, 97-127.

85. Mortlock, R. F.; Bell, A. T.; Chakraborty, A. K.; Radke, C. J. The Journal of Physical Chemistry 1991, 95, 4501-4506.

86. Mortlock, R. F.; Bell, A. T.; Radke, C. J. The Journal of Physical Chemistry 1991, 95, 7847-7851.

87. Hendricks, W. M.; Bell, A. T.; Radke, C. J. The Journal of Physical Chemistry 1991, 95, 9519-9524.

88. Mortlock, R. F.; Bell, A. T.; Radke, C. J. The Journal of Physical Chemistry 1992, 96, $2968-2975$.

89. Mortlock, R. F.; Bell, A. T.; Radke, C. J. The Journal of Physical Chemistry 1993, 97, 767-774.

90. Mortlock, R. F.; Bell, A. T.; Radke, C. J. The Journal of Physical Chemistry 1993, 97, $775-782$.

91. Ginter, D. M.; Bell, A. T.; Radke, C. J. Journal of Magnetic Resonance (1969) 1989, 81, 217-219.

92. Ginter, D. M.; Radke, C. J.; Bell, A. T. Applications of MAS-NMR Spectroscopy to the Study of Faujasite Synthesis. In Studies in Surface Science and Catalysis; Jacobs, P. A., van Santen, R. A., Eds.; Elsevier: Amsterdam, 1989; Vol. 49, pp 161-168. 
93. Ginter, D. M.; Went, G. T.; Bell, A. T.; Radke, C. J. Zeolites 1992, 12, 733-741.

94. Hendricks, W. M.; Bell, A. T.; Radke, C. J. The Journal of Physical Chemistry 1991, 95, 9513-9518.

95. Gittleman, C. S.; Lee, S. S.; Bell, A. T.; Radke, C. J. Microporous Materials 1995, 3, 511 530.

96. Gittleman, C. S.; Watanabe, K.; Bell, A. T.; Radke, C. J. Microporous Materials 1996, 6, 131-150.

97. Gittleman, C. S.; Bell, A. T.; Radke, C. J. Catalysis Letters 1996, 38, 1-9.

98. Chang, C. D.; Bell, A. T. Catalysis Letters 1991, 8, 305-316.

99. E. M Flanigen, E. M., Pure Appl. Chem. 1980, 52, 2191-2211.

100. Shen, V.; Bell, A. T. Microporous Materials 1996, 7, 187-199.

101. Shen, V.; Watanabe, K.; Bell, A. T. The Journal of Physical Chemistry B 1997, 101, 2207-2212.

102. Bell, A. T. Colloids and Surfaces A: Physicochemical and Engineering Aspects 1999, 158, 221-234.

103. Went, G. T.; Leu, L. J.; Lombardo, S. J.; Bell, A. T. The Journal of Physical Chemistry 1992, 96, 2235-2241.

104. Went, G. T.; Leu, L.-j.; Bell, A. T. Journal of Catalysis 1992, 134, 479-491.

105. Went, G. T.; Leu, L.-J.; Rosin, R. R.; Bell, A. T. Journal of Catalysis 1992, 134, 492-505.

106. Boffa, A. B.; Bell, A. T.; Somorjai, G. A. Journal of Catalysis 1993, 139, 602-610.

107. Khodakov, A.; Yang, J.; Su, S.; Iglesia, E.; Bell, A. T. Journal of Catalysis 1998, 177, $343-351$.

108. Su, S. C.; Bell, A. T. The Journal of Physical Chemistry B 1998, 102, 7000-7007. 
109. Khodakov, A.; Olthof, B.; Bell, A. T.; Iglesia, E. Journal of Catalysis 1999, 181, 205-216.

110. Chen, K.; Khodakov, A.; Yang, J.; Bell, A. T.; Iglesia, E. Journal of Catalysis 1999, 186, $325-333$.

111. Rulkens, R.; Male, J. L.; Terry, K. W.; Olthof, B.; Khodakov, A.; Bell, A. T.; Iglesia, E.; Tilley, T. D. Chemistry of Materials 1999, 11, 2966-2973.

112. Olthof, B.; Khodakov, A.; Bell, A. T.; Iglesia, E. The Journal of Physical Chemistry B 2000, 104, 1516-1528.

113. Chen, K.; Iglesia, E.; Bell, A. T. Journal of Catalysis 2000, 192, 197-203.

114. Xie, S.; Iglesia, E.; Bell, A. T. Langmuir 2000, 16, 7162-7167.

115. Male, J. L.; Niessen, H. G.; Bell, A. T.; Don Tilley, T. Journal of Catalysis 2000, 194, 431-444.

116. Pak, C.; Bell, A. T.; Tilley, T. D. Journal of Catalysis 2002, 206, 49-59.

117. Argyle, M. D.; Chen, K.; Bell, A. T.; Iglesia, E. Journal of Catalysis 2002, 208, 139-149.

118. Waku, T.; Argyle, M. D.; Bell, A. T.; Iglesia, E. Industrial \& Engineering Chemistry Research 2003, 42, 5462-5466.

119. Dai, H.; Bell, A. T.; Iglesia, E. Journal of Catalysis 2004, 221, 491-499.

120. Argyle, M. D.; Chen, K.; Resini, C.; Krebs, C.; Bell, A. T.; Iglesia, E. The Journal of Physical Chemistry B 2004, 108, 2345-2353.

121. Evans, O. R.; Bell, A. T.; Tilley, T. D. Journal of Catalysis 2004, 226, 292-300.

122. Dai, H.; Chen, L.; Don Tilley, T.; lglesia, E.; Bell, A. T. Studies in Surface Science and Catalysis 2004, 147, 679-684.

123. Argyle, M. D.; Chen, K.; Iglesia, E.; Bell, A. T. The Journal of Physical Chemistry B 2005, 109, 2414-2420. 
124. Yang, S.; Iglesia, E.; Bell, A. T. The Journal of Physical Chemistry B 2005, 109, 89879000.

125. Hess, C.; Drake, I. J.; Hoefelmeyer, J. D.; Tilley, T. D.; Bell, A. T. Catalysis Letters 2005 , $105,1-8$.

126. Khaliullin, R. Z.; Bell, A. T.; Head-Gordon, M. The Journal of Physical Chemistry B 2005, 109, 17984-17992.

127. Ruddy, D. A.; Ohler, N. L.; Bell, A. T.; Tilley, T. D. Journal of Catalysis 2006, 238, 277285.

128. Kilos, B.; Bell, A. T.; Iglesia, E. The Journal of Physical Chemistry C 2009, 113, 28302836.

129. Dinse, A.; Schomacker, R.; Bell, A. T. Physical Chemistry Chemical Physics 2009, 11, 6119-6124.

130. Bronkema, J. L.; Bell, A. T. The Journal of Physical Chemistry C 2007, 111, 420-430.

131. Goodrow, A.; Bell, A. T. The Journal of Physical Chemistry C 2007, 111, 14753-14761.

132. Bronkema, J. L.; Leo, D. C.; Bell, A. T. The Journal of Physical Chemistry C 2007, 111, $14530-14540$.

133. Bronkema, J. L.; Bell, A. T. Catalysis Letters 2008, 122, 1-8.

134. Bronkema, J. L.; Bell, A. T. The Journal of Physical Chemistry C 2008, 112, 6404-6412.

135. Goodrow, A.; Bell, A. T. The Journal of Physical Chemistry C 2008, 112, 13204-13214.

136. Goodrow, A.; Bell, A. T.; Head-Gordon, M. The Journal of Physical Chemistry C 2009, $113,19361-19364$.

137. Vining, W. C.; Goodrow, A.; Strunk, J.; Bell, A. T. Journal of Catalysis 2010, 270, 163171. 
138. Vining, W. C.; Strunk, J.; Bell, A. T. Journal of Catalysis 2011, 281, 222-230.

139. Vining, W. C.; Strunk, J.; Bell, A. T. Journal of Catalysis 2012, 285, 160-167.

140. Shapovalov, V.; Fievez, T.; Bell, A. T. The Journal of Physical Chemistry C 2012, 116, $18728-18735$.

141. Khaliullin, R. Z.; Bell, A. T. The Journal of Physical Chemistry B 2002, 106, 7832-7838.

142. Ohler, N.; Bell, A. T. The Journal of Physical Chemistry B 2005, 109, 23419-23429.

143. Bell, A. T. Science 2003, 299, 1688-1691.

144. Shustorovich, E.; Bell, A. T. Surface Science 1988, 205, 492-512.

145. Bell, A. T.; Shustorovich, E. Journal of Catalysis 1990, 121, 1-6.

146. Shustorovich, E.; Bell, A. T. Surface Science 1989, 222, 371-382.

147. Bell, A. T.; Shustorovich, E. Surface Science 1990, 235, 343-350.

148. Shustorovich, E.; Bell, A. T. Surface Science 1991, 253, 386-394.

149. Relationship of Reaction Energetics to the Mechanism and Kinetics of Heterogeneously Catalyzed Reactions. In Metal-Surface Reaction Energetics: Theory and Applications to Heterogeneous Catalysis, Chemisorption, and Surface Diffusion; Shustorovich E., Eds.; VCH Publishers: New York, 1991; Chap. 5, pp 191-227.

150. Shustorovich, E.; Bell, A. T. Surface Science 1992, 268, 397-405.

151. Shustorovich, E.; Bell, A. T. Surface Science 1993, 289, 127-138.

152. Lombardo, S. J.; Bell, A. T. Surface Science 1988, 206, 101-123.

153. Lombardo, S. J.; Bell, A. T. Surface Science 1991, 245, 213-224.

154. Lombardo, S. J.; Bell, A. T. Surface Science Reports 1991, 13, 3-72. 
155. Theodorou D.N.; Snurr R.Q.; Bell A.T. Molecular Dynamics and Diffusion in Microporous Materials. In Comprehensive Supramolecular Chemistry; Alberti G., Bein T., Eds.; Pergamon: New York, 1996; Vol. 7, pp. 507.

156. Maginn, E. J.; Snurr, R. Q.; Bell, A. T.; Theodorou, D. N. Studies in Surface Science and Catalysis 1997, 105, 1851-1858.

157. "Molecular Simulation of Adsorption and Diffusion in Zeolites", (with E.J. Maginn and D.N. Theodorou), in Handbook of Heterogeneous Catalysis, G. Ertl, H. Knözinger and J. Weitkamp, Eds., VCH, Germany 1997; 3, pp. 1165-1188.

158. June, R. L.; Bell, A. T.; Theodorou, D. N. The Journal of Physical Chemistry 1990, 94, 1508-1516.

159. June, R. L.; Bell, A. T.; Theodorou, D. N. The Journal of Physical Chemistry 1990, 94, $8232-8240$.

160. June, R. L.; Bell, A. T.; Theodorou, D. N. The Journal of Physical Chemistry 1991, 95, $8866-8878$.

161. Snurr, R. Q.; June, R. L.; Bell, A. T.; Theodorou, D. N. Molecular Simulation 1991, 8, 73 92.

162. June, R. L.; Bell, A. T.; Theodorou, D. N. The Journal of Physical Chemistry 1992, 96, 1051-1060.

163. Snurr, R. Q.; Bell A.T.; Theodorou D.N. Proceedings from the Ninth International Zeolite Conference 1992, 71-78.

164. Snurr, R. Q.; Bell, A. T.; Theodorou, D. N. The Journal of Physical Chemistry 1993, 97, 13742-13752. 
165. Snurr, R. Q.; Bell, A. T.; Theodorou, D. N. The Journal of Physical Chemistry 1994, 98, 5111-5119.

166. Snurr, R. Q.; Bell, A. T.; Theodorou, D. N. The Journal of Physical Chemistry 1994, 98, 11948-11961.

167. Maginn, E. J.; Bell, A. T.; Theodorou, D. N. The Journal of Physical Chemistry 1993, 97, 4173-4181.

168. Maginn, E. J.; Bell, A. T.; Theodorou, D. N. The Journal of Physical Chemistry 1995, 99, 2057-2079.

169. Maginn, E. J.; Bell, A. T.; Theodorou, D. N. The Journal of Physical Chemistry 1996, $100,7155-7173$.

170. Coppens, M.-O.; Bell, A. T.; Chakraborty, A. K. Chemical Engineering Science 1998, 53, 2053-2061.

171. Coppens, M.-O.; Bell, A. T.; Chakraborty, A. K. Chemical Engineering Science 1999, 54, $3455-3463$.

172. Coppens. M.; Bell A.T.; Chakraborty A. K. Influence of Occupancy and Pore Network Topology on Tracer and Transport Diffusion in Zeolites. In Scientific Computing in Chemical Engineering; Keil F., Mackens W., Voss H., Werther J., Eds.; SV: Berlin 1999; pp. 200-207.

173. Trout, B. L.; Chakraborty, A. K.; Bell, A. T. The Journal of Physical Chemistry 1996, $100,4173-4179$.

174. Trout, B. L.; Chakraborty, A. K.; Bell, A. T. The Journal of Physical Chemistry 1996, $100,17582-17592$.

175. Bell, A. T. Catalysis Today 1997, 38, 151-156. 
176. Gonzales, N. O.; Chakraborty, A. K.; Bell, A. T. Catalysis Letters 1998, 50, 135-139.

177. Schilke, T. C.; Fisher, I. A.; Bell, A. T. Catalysis Letters 1998, 54, 105-111.

178. Ryder, J. A.; Chakraborty, A. K.; Bell, A. T. The Journal of Physical Chemistry B 2002, 106, 7059-7064.

179. Bell, A. T. Molecular Physics 2004, 102, 319-329.

180. Peters, B.; Bell, A. T.; Chakraborty, A. The Journal of Chemical Physics 2004, 121, 44534460.

181. Peters, B.; Bell, A. T.; Chakraborty, A. The Journal of Chemical Physics 2004, 121, 44614466.

182. Zimmerman, P. M.; Tranca, D. C.; Gomes, J.; Lambrecht, D. S.; Head-Gordon, M.; Bell, A. T. Journal of the American Chemical Society 2012, 134, 19468-19476.

183. Tranca, D. C.; Zimmerman, P. M.; Gomes, J.; Lambrecht, D.; Keil, F. J.; Head-Gordon, M.; Bell, A. T. The Journal of Physical Chemistry C 2015, 119, 28836-28853.

184. Ryder, J. A.; Chakraborty, A. K.; Bell, A. T. The Journal of Physical Chemistry B 2000, 104, 6998-7011.

185. Gomes, J.; Zimmerman, P. M.; Head-Gordon, M.; Bell, A. T. The Journal of Physical Chemistry C 2012, 116, 15406-15414.

186. Zimmerman, P. M.; Head-Gordon, M.; Bell, A. T. Journal of Chemical Theory and Computation 2011, 7, 1695-1703.

187. Li, Y.-P.; Gomes, J.; Mallikarjun Sharada, S.; Bell, A. T.; Head-Gordon, M. The Journal of Physical Chemistry C 2015, 119, 1840-1850.

188. Heyden, A.; Bell, A. T.; Keil, F. J. The Journal of Chemical Physics 2005, 123, 224101. 
189. Goodrow, A.; Bell, A. T.; Head-Gordon, M. The Journal of Chemical Physics 2008, 129, 174109.

190. Goodrow, A.; Bell, A. T.; Head-Gordon, M. The Journal of Chemical Physics 2009, 130, 244108.

191. Goodrow, A.; Bell, A. T.; Head-Gordon, M. Chemical Physics Letters 2010, 484, 392398.

192. Behn, A.; Zimmerman, P. M.; Bell, A. T.; Head-Gordon, M. Journal of Chemical Theory and Computation 2011, 7, 4019-4025.

193. Behn, A.; Zimmerman, P. M.; Bell, A. T.; Head-Gordon, M. The Journal of Chemical Physics 2011, 135, 224108.

194. Sharada, S. M.; Bell, A. T.; Head-Gordon, M. The Journal of Chemical Physics 2014, $140,164115$.

195. Peters, B.; Heyden, A.; Bell, A. T.; Chakraborty, A. The Journal of Chemical Physics 2004, 120, 7877-7886.

196. Peters, B.; Liang, W.; Bell, A. T.; Chakraborty, A. The Journal of Chemical Physics 2003, 118, 9533-9541.

197. Mallikarjun Sharada, S.; Zimmerman, P. M.; Bell, A. T.; Head-Gordon, M. Journal of Chemical Theory and Computation 2012, 8, 5166-5174.

198. Heyden, A.; Peters, B.; Bell, A. T.; Keil, F. J. The Journal of Physical Chemistry B 2005, 109, 1857-1873.

199. Heyden, A.; Hansen, N.; Bell, A. T.; Keil, F. J. The Journal of Physical Chemistry B 2006, $110,17096-17114$ 
200. Hansen, N.; Heyden, A.; Bell, A. T.; Keil, F. J. The Journal of Physical Chemistry C 2007, 111, 2092-2101.

201. Heyden, A.; Bell, A. T.; Keil, F. J. Journal of Catalysis 2005, 233, 26-35.

202. Janda, A.; Vlaisavljevich, B.; Lin, L.-C.; Mallikarjun Sharada, S.; Smit, B.; Head-Gordon, M.; Bell, A. T. The Journal of Physical Chemistry C 2015, 119, 10427-10438.

203. Janda, A.; Vlaisavljevich, B.; Lin, L.-C.; Smit, B.; Bell, A. T. Journal of the American Chemical Society 2016, 138, 4739-4756.

204. Swisher, J. A.; Hansen, N.; Maesen, T.; Keil, F. J.; Smit, B.; Bell, A. T. The Journal of Physical Chemistry C 2010, 114, 10229-10239.

205. Mallikarjun Sharada, S.; Zimmerman, P. M.; Bell, A. T.; Head-Gordon, M. The Journal of Physical Chemistry C 2013, 117, 12600-12611. 


\section{List of Figures}

Figure 1. Sequence of elementary reactions expected to occur when a hydrocarbon monomer enters a discharge zone of a DC plasma reactor. ${ }^{8}$

Figure 2. The rate of polymerization, which is the sum of gas and surface propagation steps was determined by solving the material balance equations that describe the monomer and free radical concentrations as a function of axial and radial position in the flow reactor. Predicted and experimental rates of polymer deposition as a function of monomer flow rate are one illustration of this model fit. ${ }^{8}$

Figure 3. Dependence of the Rh-NCO and $\mathrm{Rh}-\mathrm{NO}^{\delta-}$ absorbance bands as a function of NO partial pressure. During the reduction of $\mathrm{NO}$ by $\mathrm{CO}$ over a $\mathrm{Rh} / \mathrm{SiO}_{2}$ catalyst an isocyanate group is formed on the surface of the rhodium microcrystallites. The dependence of the Rh-NCO band intensity on partial pressures of NO and CO can be interpreted with the aid of the reaction mechanism. ${ }^{24}$

Figure 4. Transient response and isotope tracer studies revealed two distinctly different forms of carbon formed on $\mathrm{Ru} / \mathrm{SiO}_{2}$ during $\mathrm{CO}$ hydrogenation. $\mathrm{C}_{\alpha}$ is highly reactive and is the principle precursor to $\mathrm{C}_{2+}$ hydrocarbons and methane. $\mathrm{C}_{\beta}$ accumulates slower than $\mathrm{C}_{\alpha}$ and resides on $\mathrm{Ru}$ and the support. ${ }^{27}$

Figure 5. Proposed mechanism of hydrocarbon synthesis from $\mathrm{CO}$ and $\mathrm{H}_{2}{ }^{18}$

Figure 6. Reaction scheme for the rapid equilibration of $\mathrm{CO}$ into adsorbed $\mathrm{CO}$ and the interconversion of dissociated $\mathrm{CO}$ into the various forms of carbon. ${ }^{61}$

Figure 7. Arrhenius plots for the formation of methanol at 10 atm and a $\mathrm{H}_{2} / \mathrm{CO}$ ratio of 3 . $^{69}$

Figure 8. Schematic illustration of the interaction of the Pd with the support. ${ }^{44}$

Figure 9. Illustration of clathrate organization around a template cation. ${ }^{98}$ 
Figure 10. Assembly of clathrates into a prospective nucleus. ${ }^{98}$

Figure 11. Quantitative ${ }^{29} \mathrm{Si}$ MAS NMR patterns, offering key evidence pointing toward a comprehensive description of the silicalite synthesis induction period. ${ }^{102}$

Figure 12. Mechanistic scheme for the TPD experiment on 3.4V/MCM-48. ${ }^{130}$

Figure 13. Mechanistic scheme for the TPO experiment on 3.4V/MCM-48. ${ }^{130}$

Figure 14. Model of the $\mathrm{VO}_{\mathrm{x}} / \mathrm{SiO}_{2}$ catalytic site. ${ }^{131}$

Figure 15. Model of the $\mathrm{VO}_{\mathrm{x}} / \mathrm{TiO}_{2}$ catalytic site. The location of the $\mathrm{O}$-vacancy is circled. ${ }^{135}$

Figure 16. (a) Location of benzene molecules adsorbed in the pore space of silicalite- 1 at $70^{\circ} \mathrm{C}$, illustrating clearly defined sites in the pore space (dark regions: 95\% probability), but also differences at low (top) and high loading (bottom). ${ }^{165}$ (b) Self-diffusivity of n-alkanes as a function of length, at $300 \mathrm{~K}$, comparing hierarchical simulations with experiments. The simulation strategy utilizes concepts from Brownian motion theory and transition state theory. ${ }^{16}$

Figure 17. Combined adsorption enthalpies and entropies from Monte Carlo simulations (blue) with overall activation parameters from experiment (red) to infer activation parameters for the chemical step (green). An independent confirmation of the overall cracking mechanism can then be obtained by using DFT calculations for the elementary cracking step(s). ${ }^{202}$ 
Table I

Reaction Mechanism for Plasma Polymerization of Unsaturated Hydrocarbons ${ }^{a}$

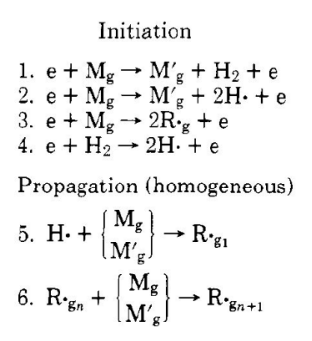

Adsorption

Termination 


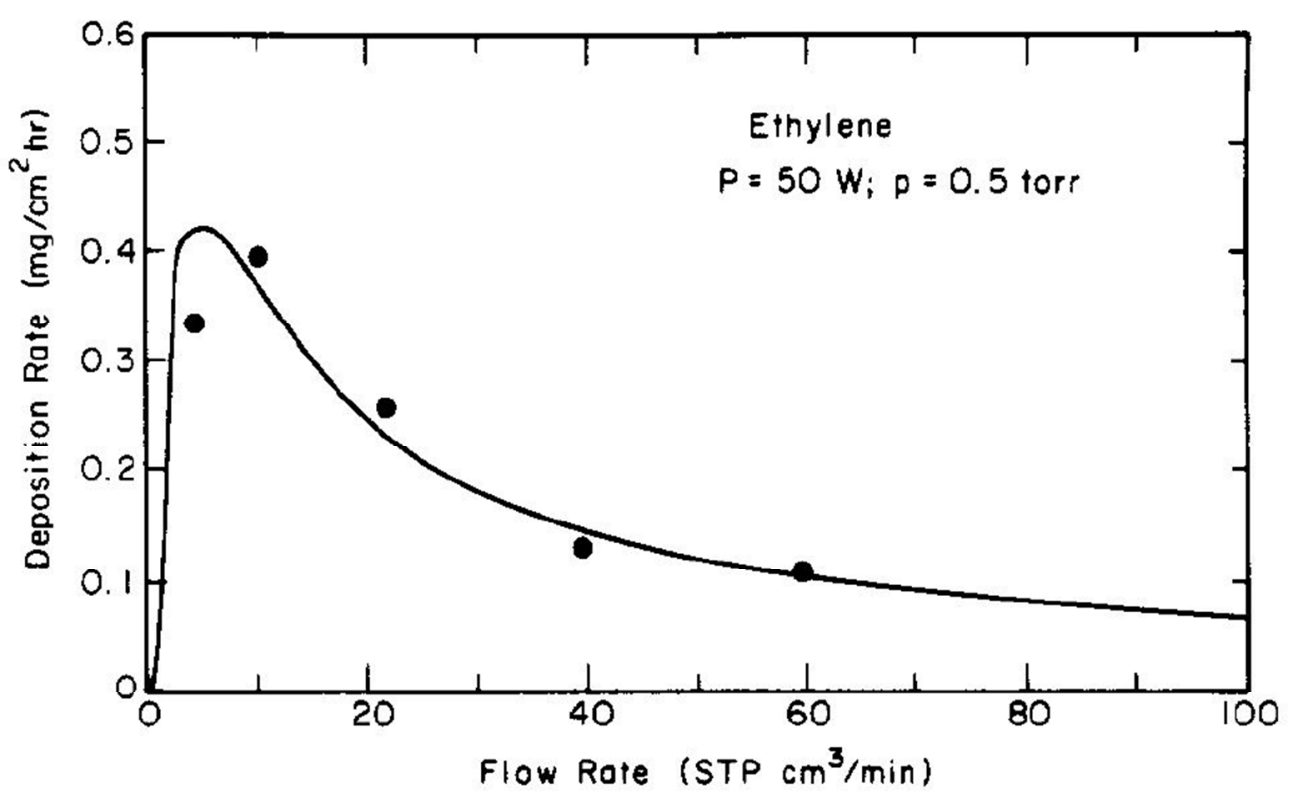

$256 \times 169 m m(96 \times 96$ DPI) 


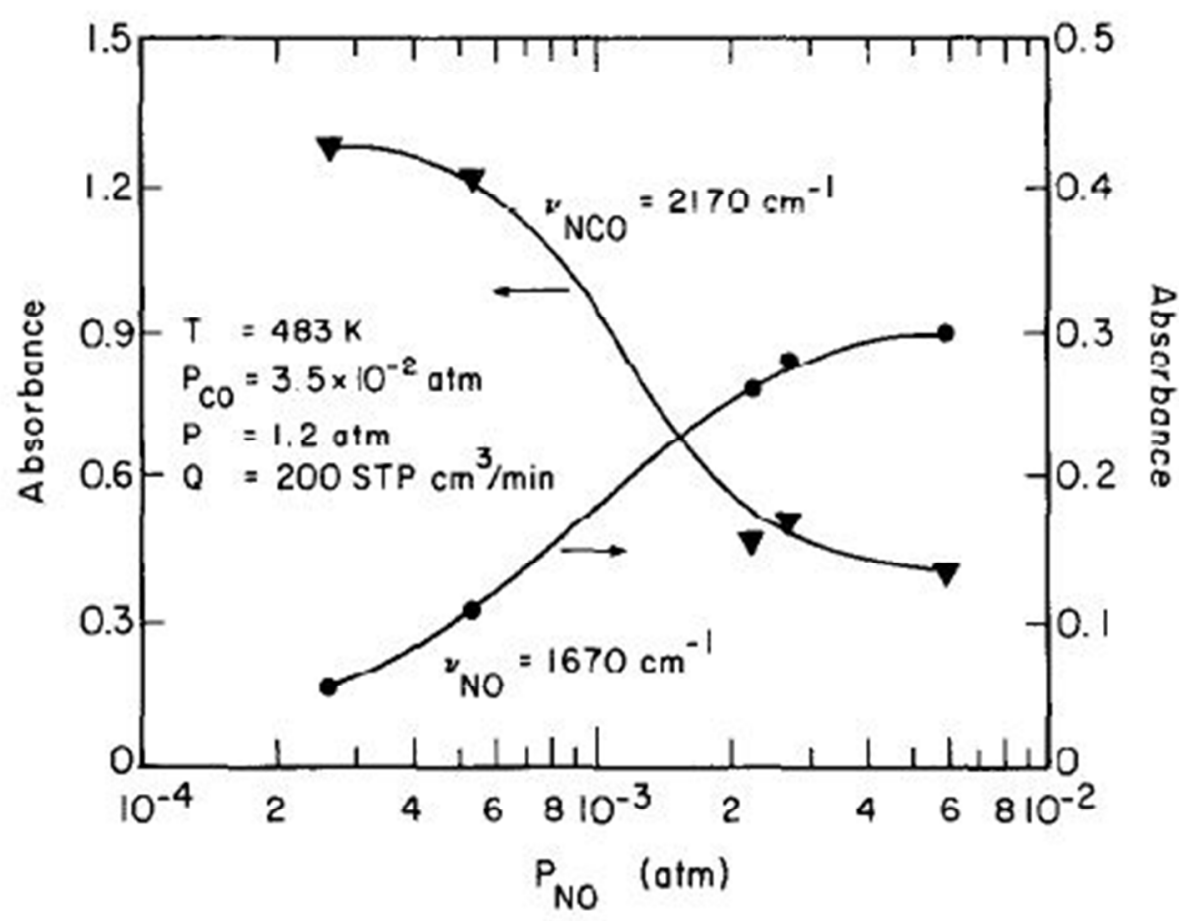

$131 \times 99 m m(96 \times 96$ DPI) 


$$
\begin{aligned}
& \text { 1. } \mathrm{NO}+\mathrm{S} \leftrightarrow \mathrm{NO}_{\mathrm{a}} \\
& \text { 2. } \mathrm{CO}+\mathrm{S} \rightarrow \mathrm{CO}_{a} \\
& \text { 3. } \mathrm{NO}_{\mathrm{a}}+\mathrm{S} \rightarrow \mathrm{N}_{\mathrm{a}}+\mathrm{O}_{\mathrm{a}} \\
& \text { 4. } \mathrm{NO}_{\mathrm{a}}+\mathrm{N}_{\mathrm{a}} \rightarrow \mathrm{N}_{2} \mathrm{O}+2 \mathrm{~S} \\
& \text { 5. } \mathrm{NO}_{\mathrm{a}}+\mathrm{N}_{\mathrm{a}} \rightarrow \mathrm{N}_{2}+\mathrm{O}_{\mathrm{a}}+\mathrm{S} \\
& \text { 6. } \mathrm{CO}_{\mathrm{a}}+\mathrm{O}_{\mathrm{a}} \rightarrow \mathrm{CO}_{2}+2 \mathrm{~S} \\
& \text { 7. } \mathrm{N}_{\mathrm{a}}+\mathrm{CO} \leftrightarrow \mathrm{NCO}_{\mathrm{a}}
\end{aligned}
$$

$128 \times 95 \mathrm{~mm}(96 \times 96 \mathrm{DPI})$ 


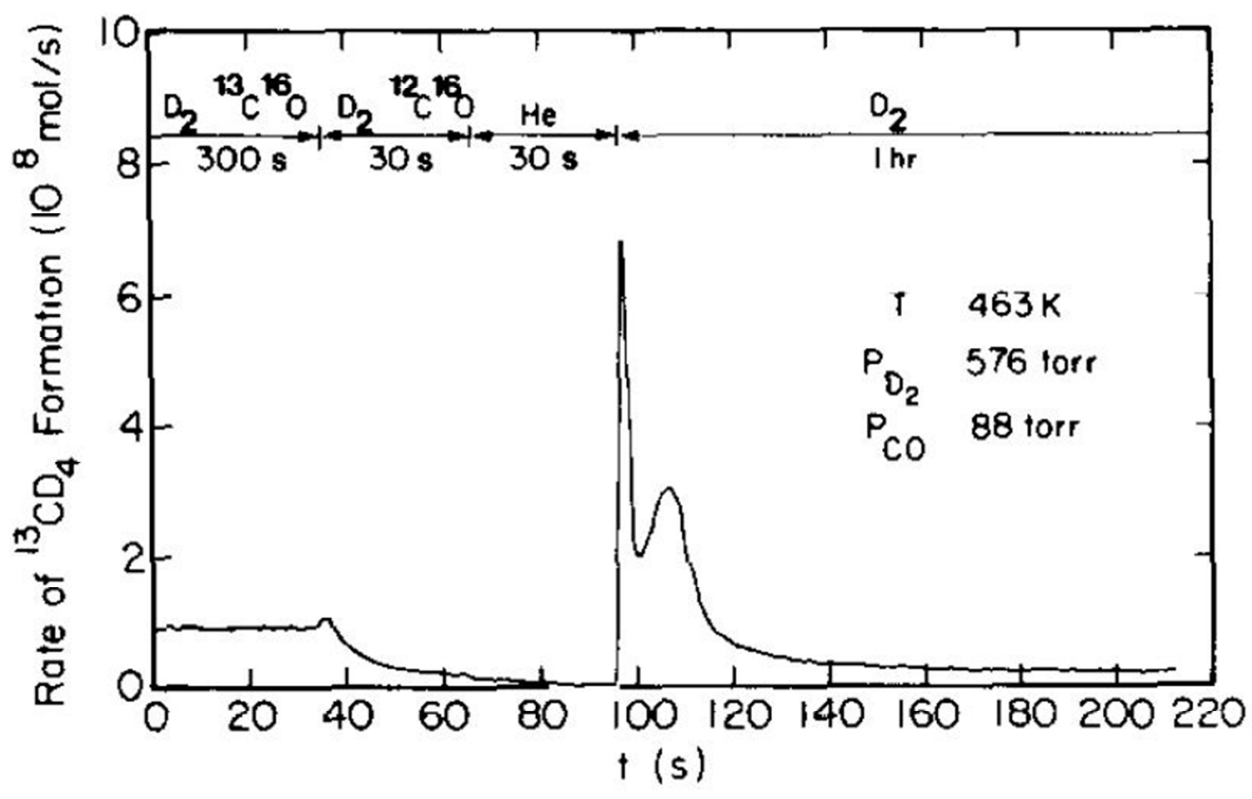

$223 \times 149 m m(96 \times 96$ DPI $)$ 


\section{$\mathrm{CO} \rightleftharpoons \mathrm{CO}_{\mathrm{s}} \stackrel{\mathrm{s}}{\longrightarrow} \mathrm{C}_{\mathrm{a}}+\mathrm{O}_{\mathrm{s}}$}

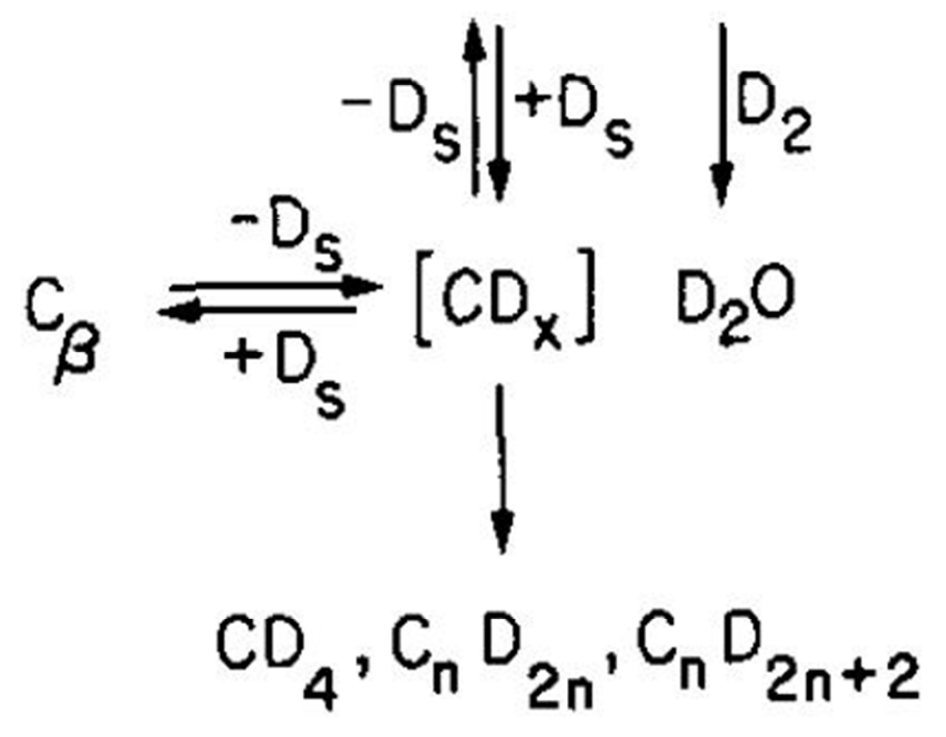

$156 \times 112 \mathrm{~mm}(96 \times 96 \mathrm{DPI})$ 


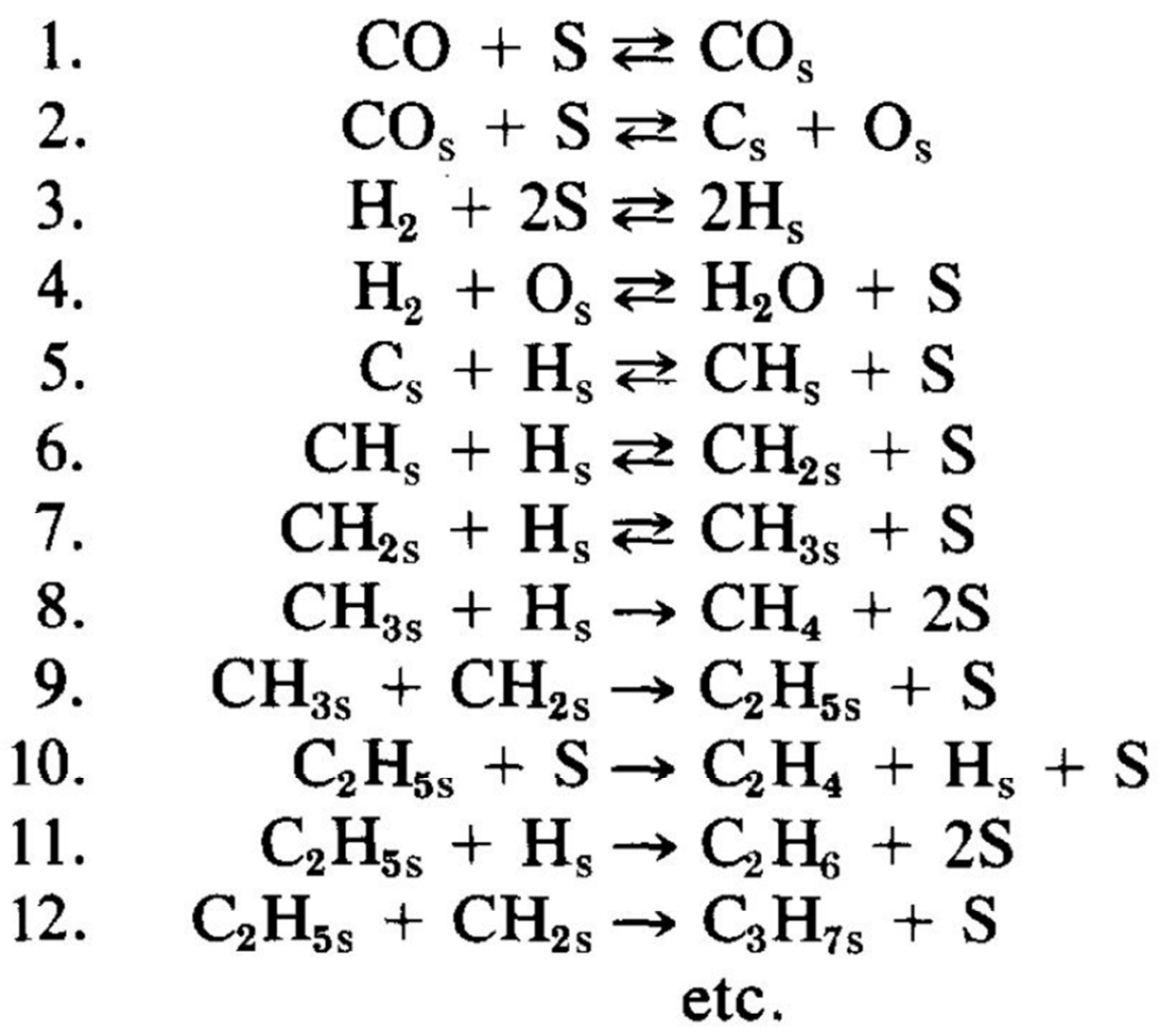

$229 \times 195 \mathrm{~mm}(96 \times 96 \mathrm{DPI})$ 


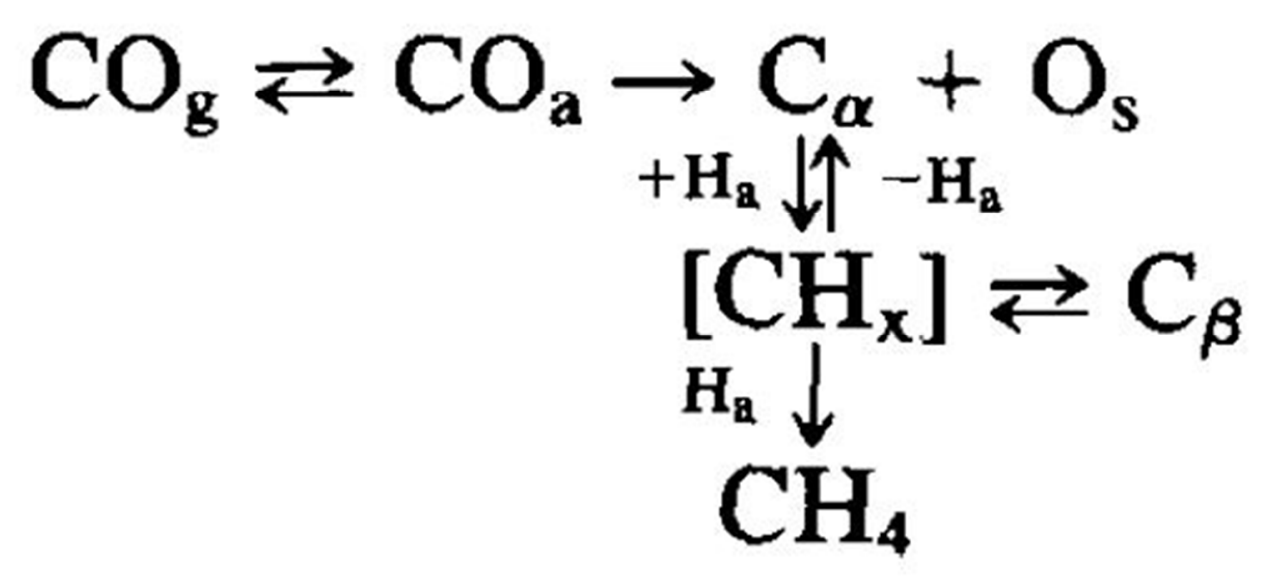

$150 \times 70 \mathrm{~mm}(96 \times 96$ DPI) 


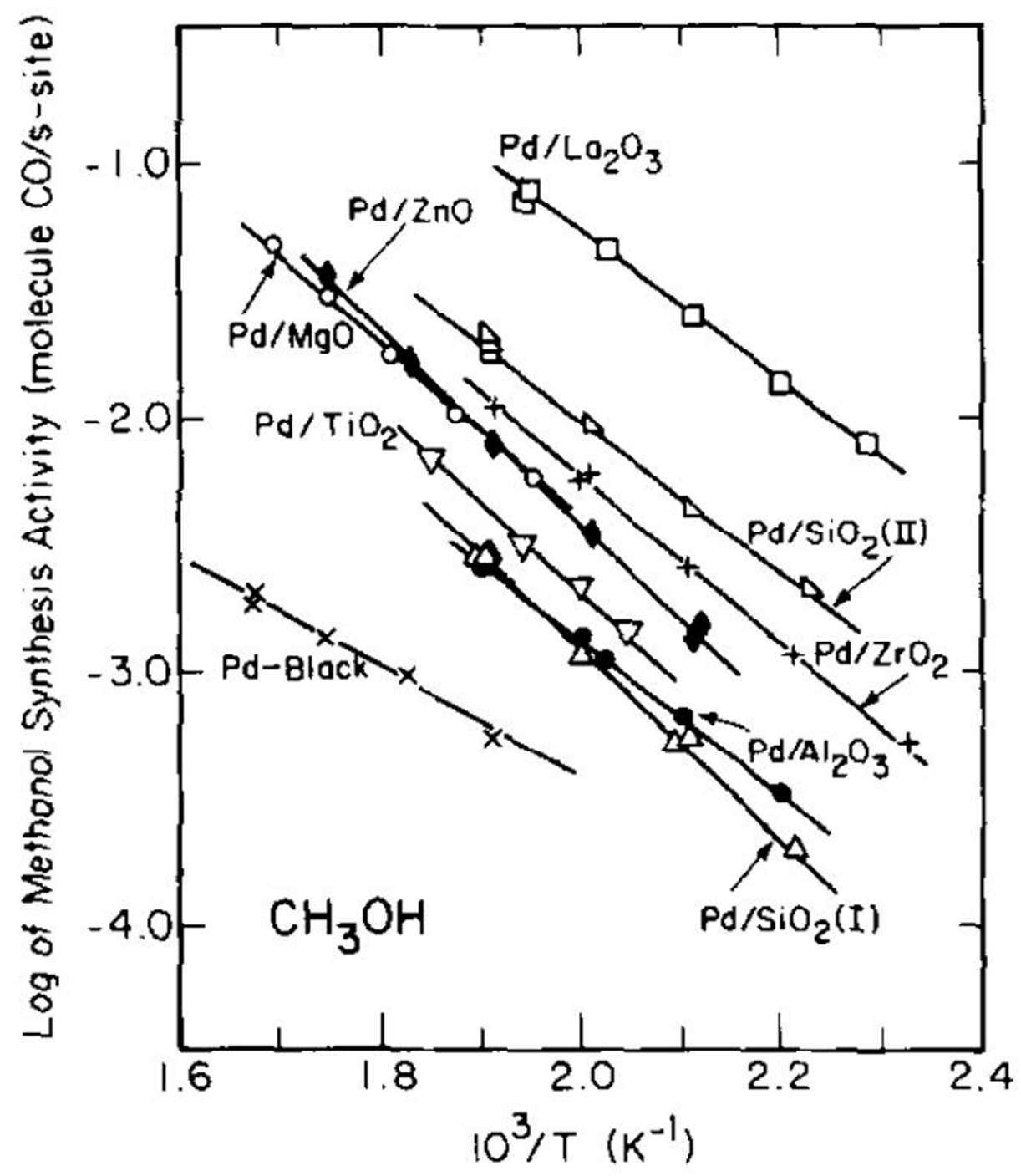

$191 \times 211 \mathrm{~mm}(96 \times 96$ DPI) 


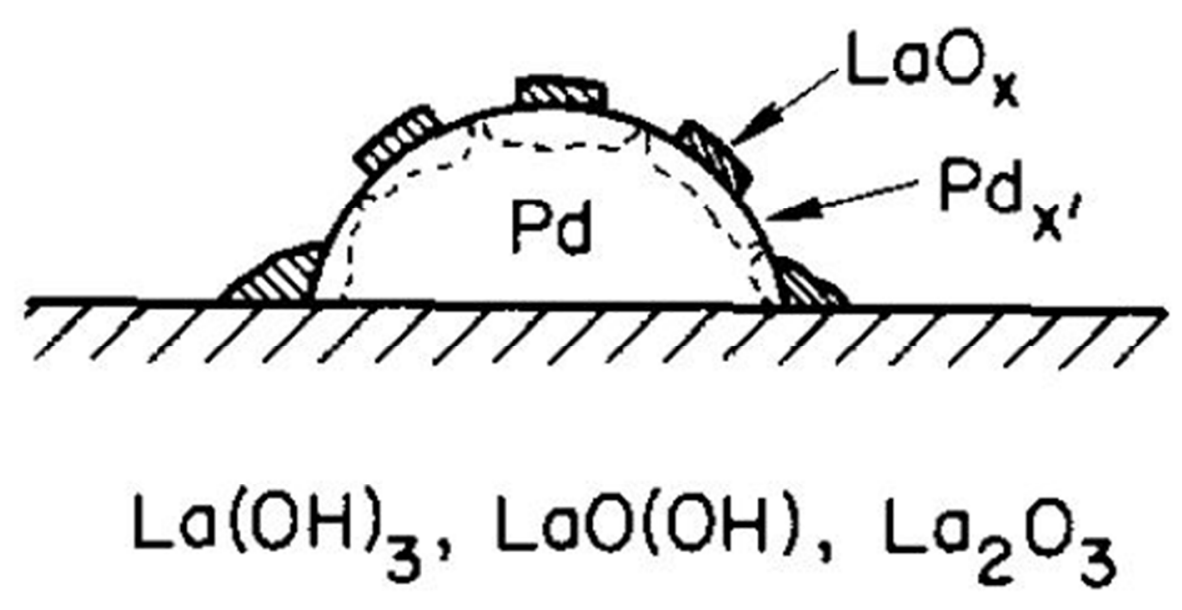

$150 \times 79 m m(96 \times 96$ DPI) 


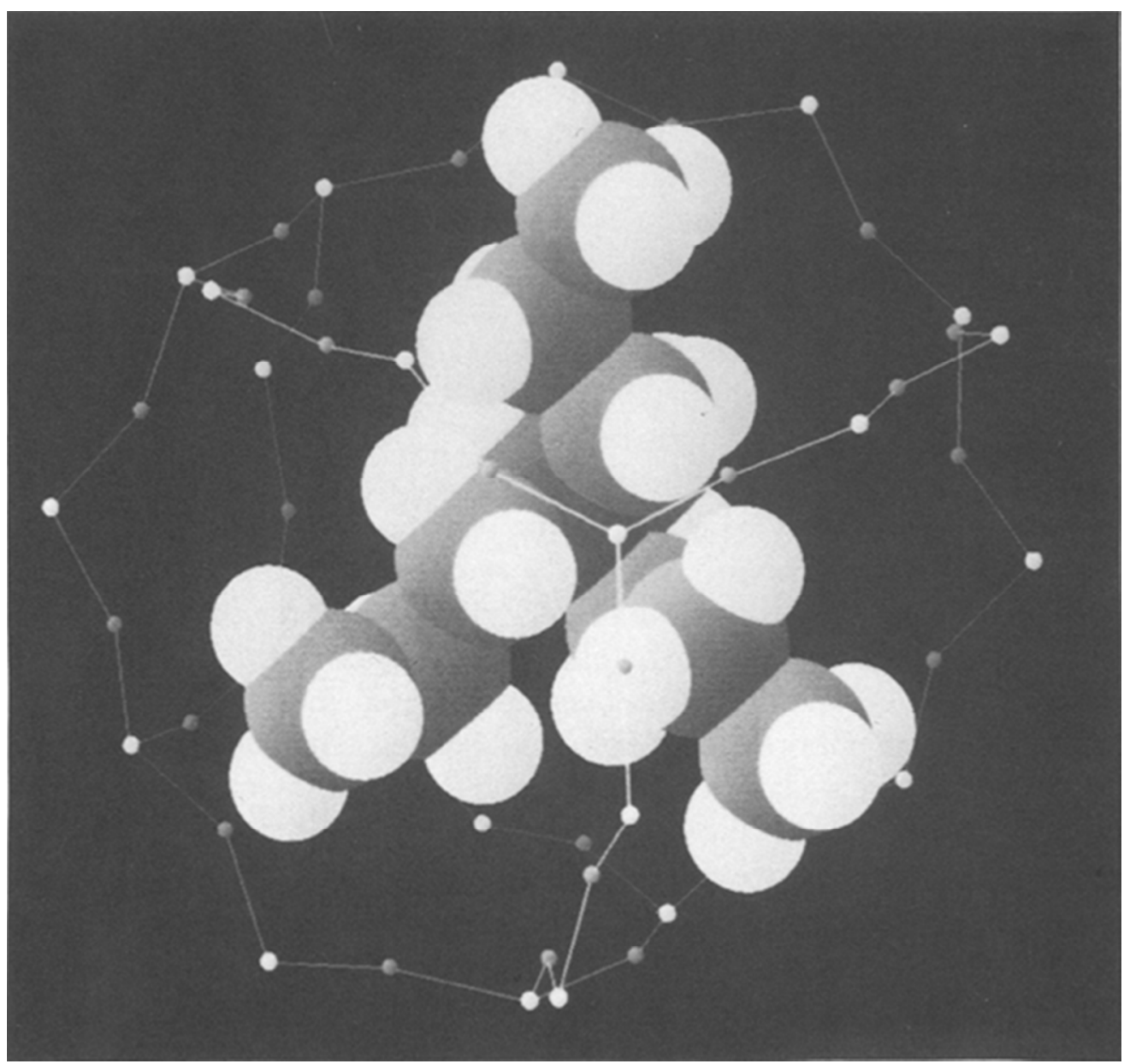

$165 \times 156 \mathrm{~mm}(96 \times 96 \mathrm{DPI})$ 


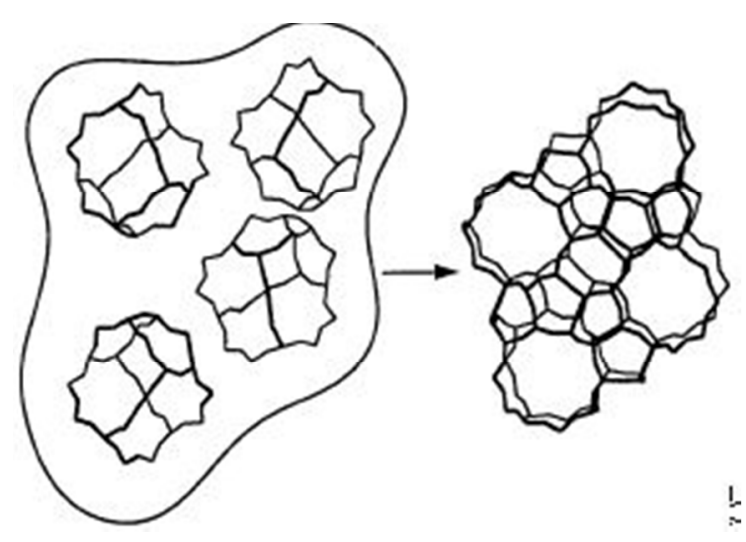

$73 \times 51 \mathrm{~mm}(96 \times 96$ DPI) 


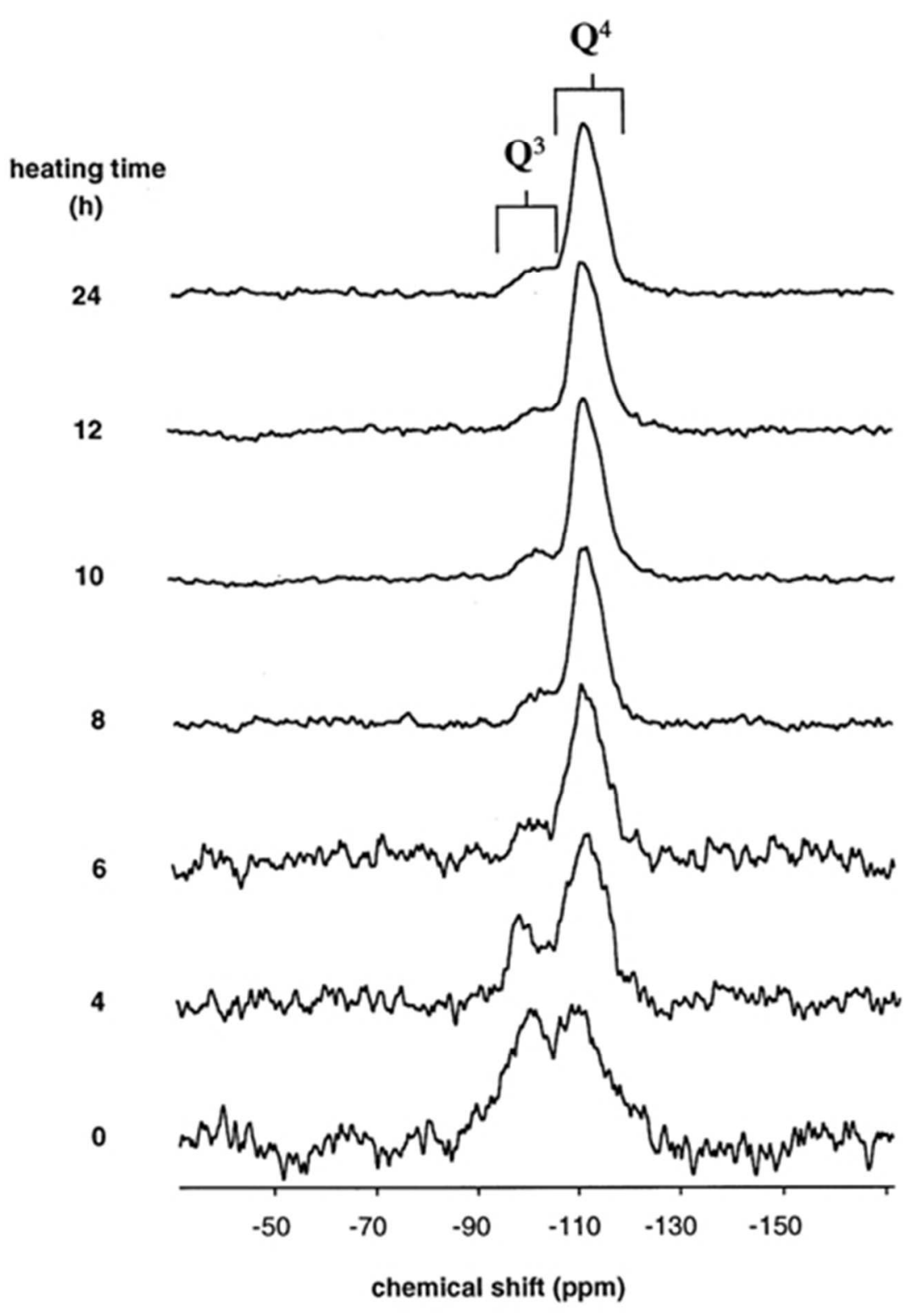

$159 \times 228 \mathrm{~mm}(72 \times 72$ DPI $)$ 


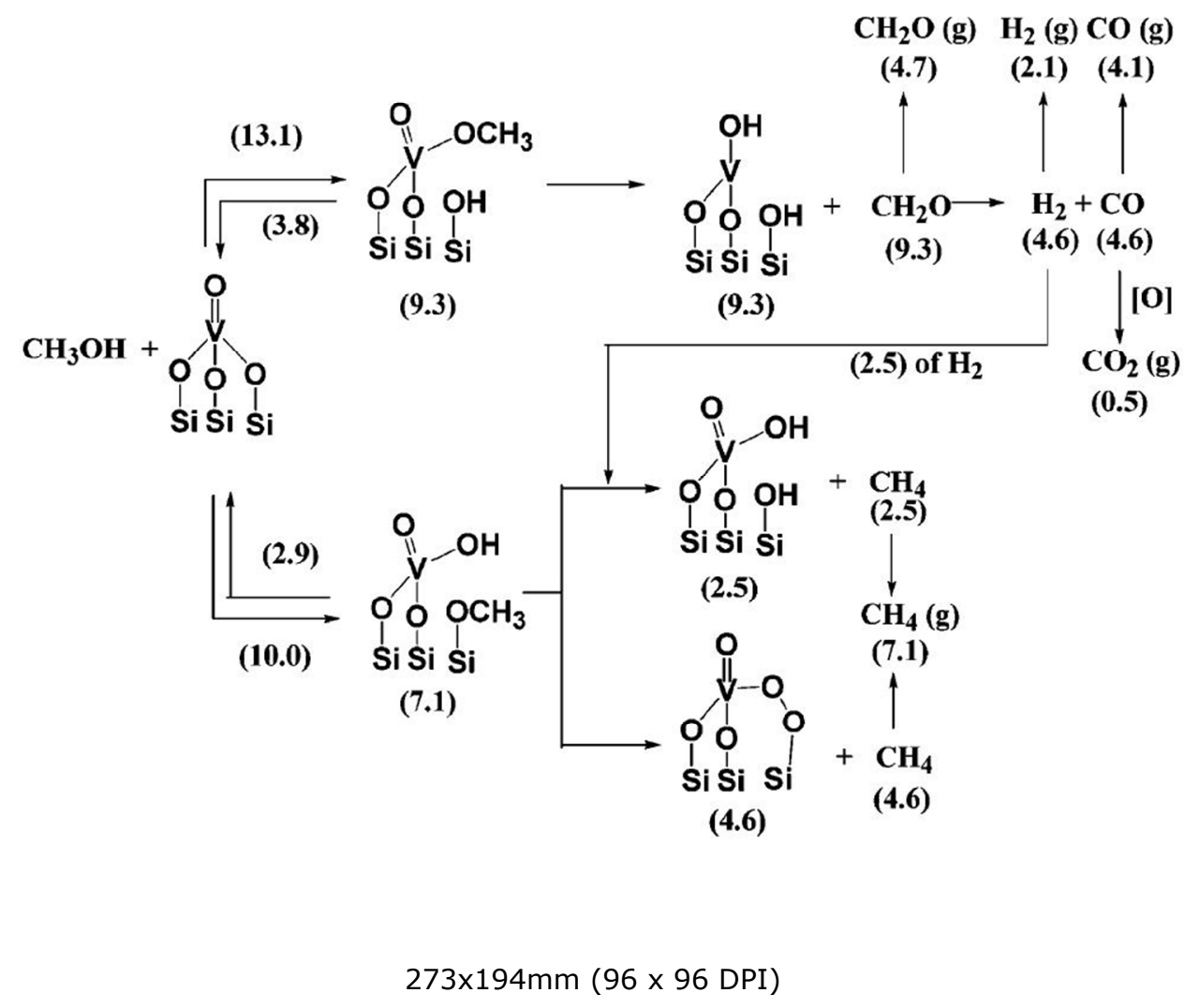




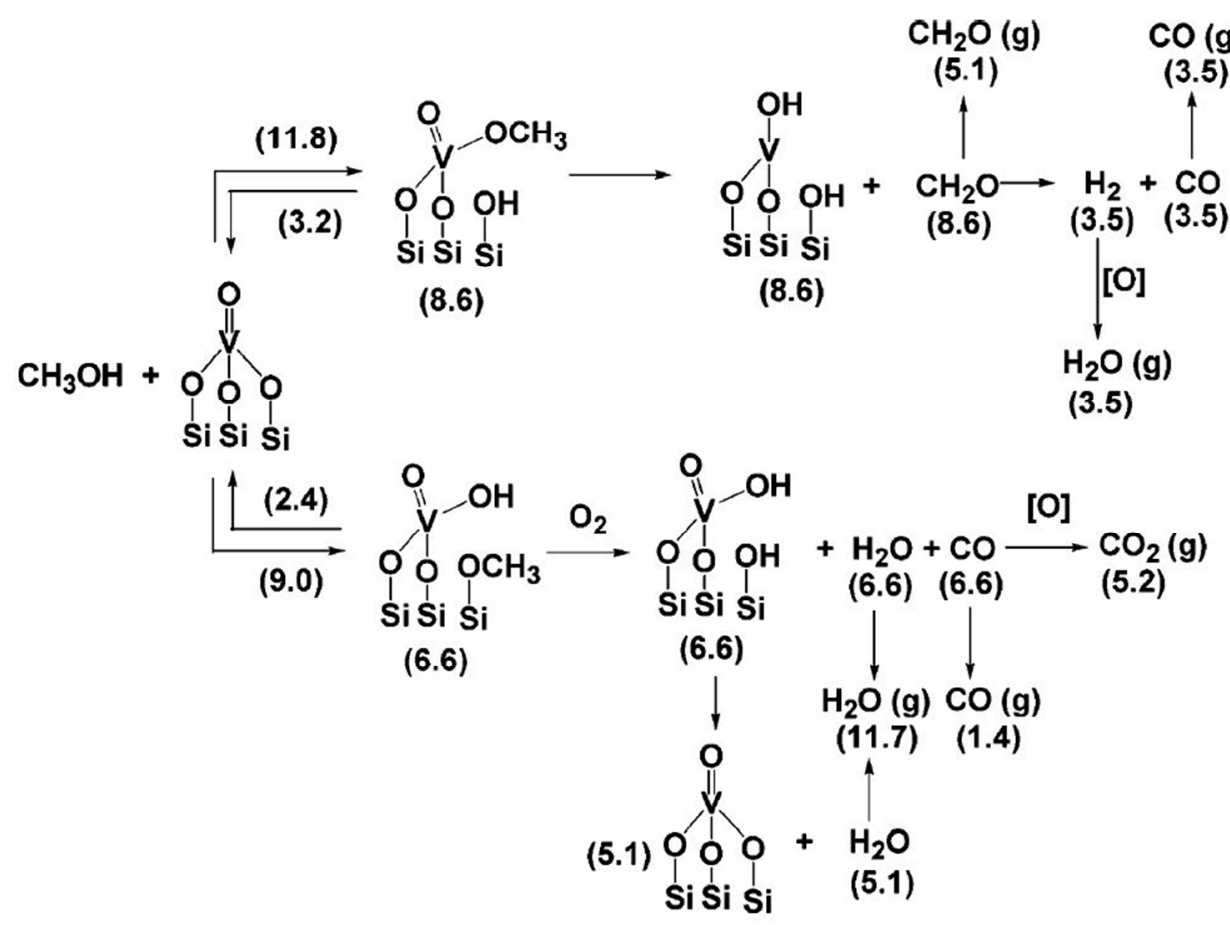

$275 \times 197 \mathrm{~mm}(96 \times 96 \mathrm{DPI})$ 


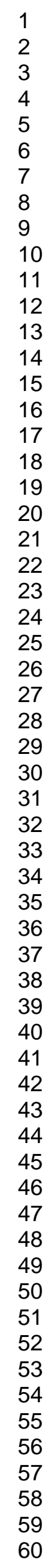

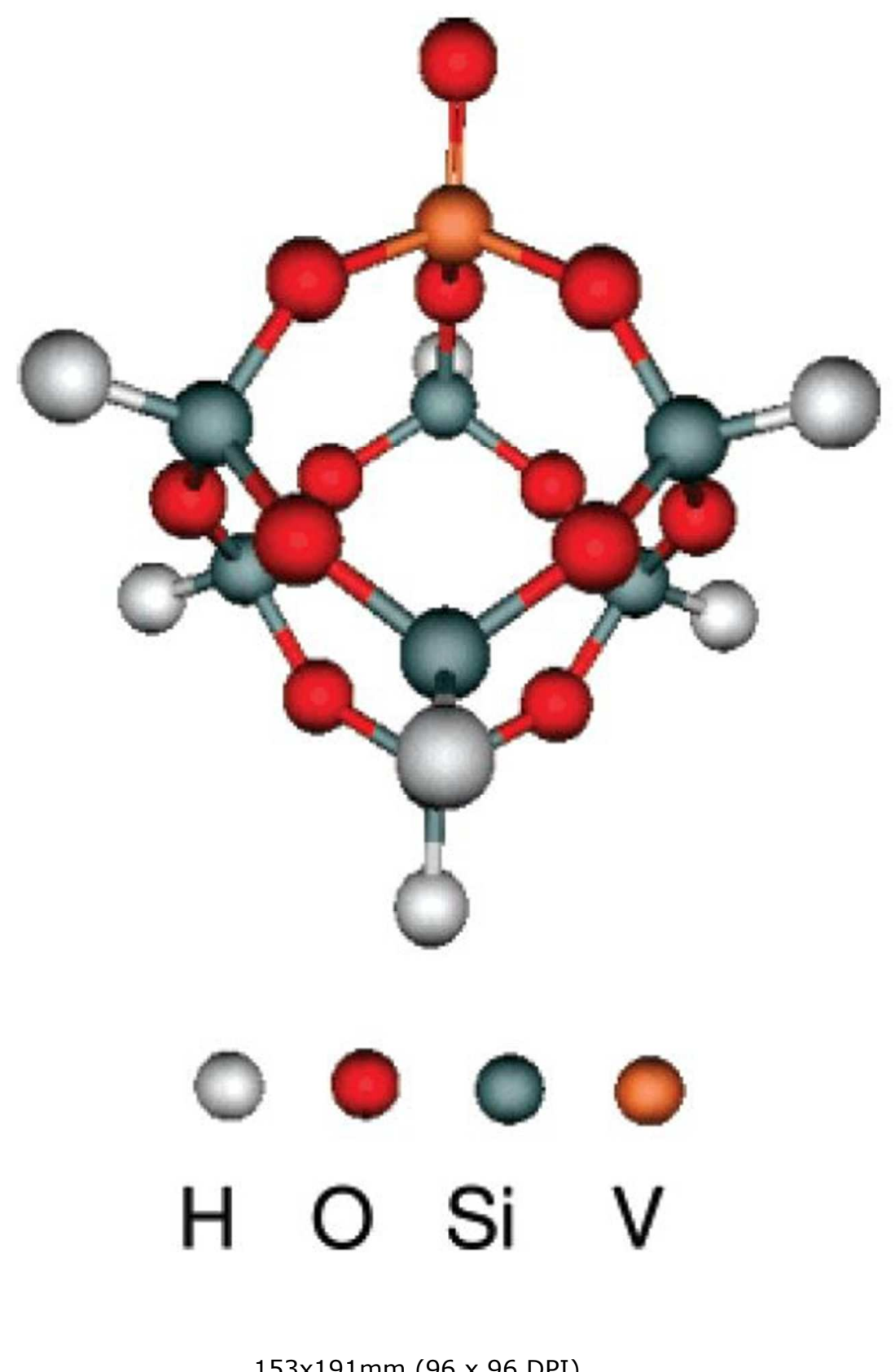

$153 \times 191 \mathrm{~mm}(96 \times 96$ DPI) 


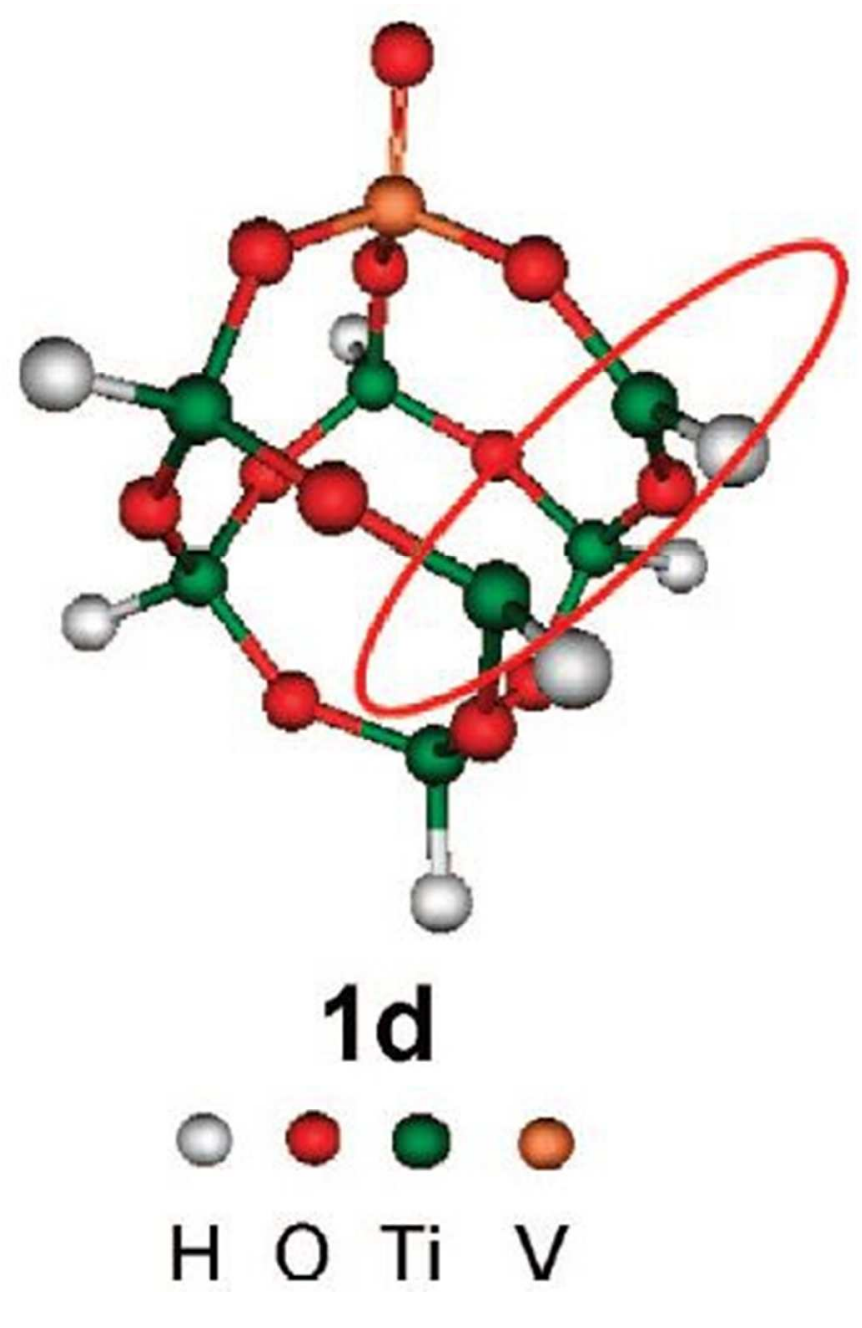

$97 \times 130 \mathrm{~mm}(96 \times 96$ DPI) 

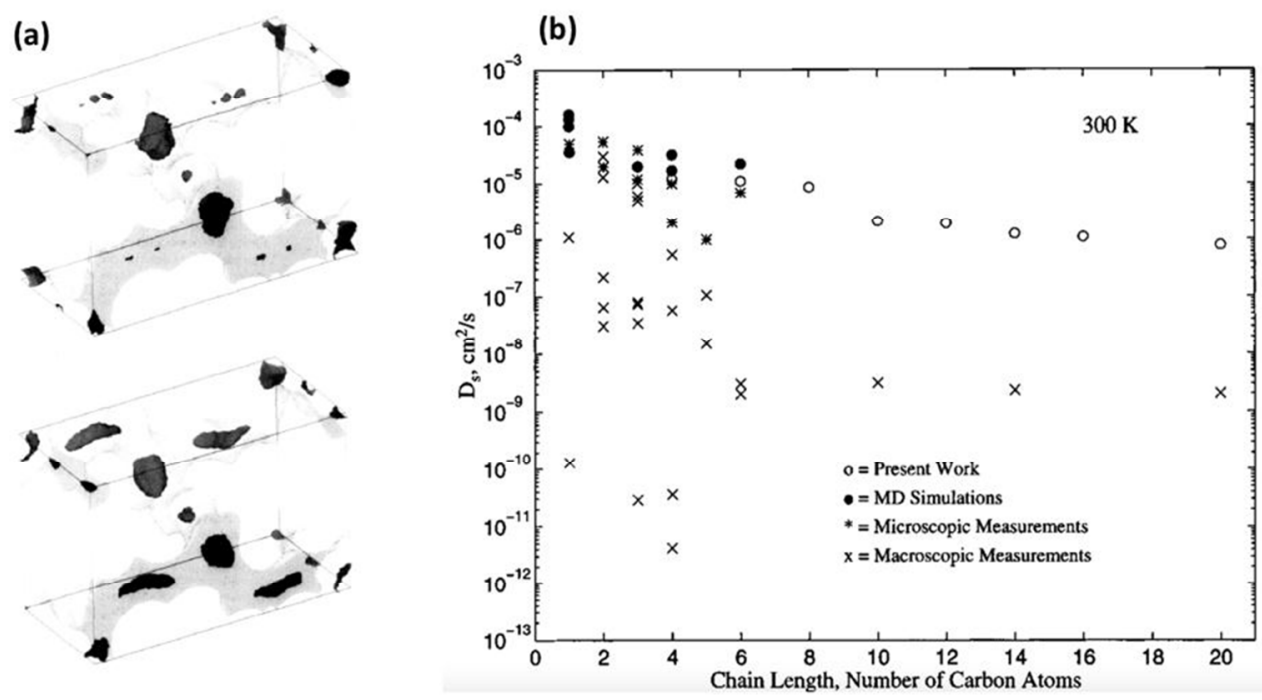

249x139mm (96 x 96 DPI) 